The following article is the final draft of the published version:

Masoud Naseri, Piero Baraldi, Michele Compare, \& Enrico Zio, 2016. Availability Assessment of Oil and Gas Processing Plants Operating under Dynamic Arctic Weather Conditions, Reliability Engineering \& System Safety, Volume 152, August 2016, pp. 6682, DOI: http://dx.doi.org/10.1016/j.ress.2016.03.004 


\title{
Availability Assessment of Oil and Gas Processing Plants Operating under Dynamic Arctic Weather Conditions
}

\author{
Masoud Naseri ${ }^{\mathrm{a}}$, Piero Baraldi ${ }^{\mathrm{b}}$, Michele Compare ${ }^{\mathrm{b}}$, Enrico Zio ${ }^{\mathrm{b}, \mathrm{c}}$ \\ ${ }^{a}$ Department of Engineering and Safety, UiT - The Arctic University of Norway, 9037, Tromsø, Norway \\ bDepartment of Energy, Polytechnic of Milan, Via Lambruschini 4, 20156, Milan, Italy \\ 'Ecole Centrale Paris-Supelec, Paris, France \\ Corresponding Author: \\ Masoud Naseri \\ Department of Engineering and Safety, UiT - The Arctic University of Norway, Post Box 6050 Lagnes, \\ 9037, Tromsø, Norway \\ Email: masoud.maseri@uit.no \\ Tel: $+47-77660327$
}

\begin{abstract}
We consider the assessment of the availability of oil and gas processing facilities operating under Arctic conditions. The novelty of the work lies in modelling the time-dependent effects of environmental conditions on the components failure and repair rates. This is done by introducing weather-dependent multiplicative factors, which can be estimated by expert judgements given the scarce data available from Arctic offshore operations. System availability is assessed considering the equivalent age of the components to account for the impacts of harsh operating conditions on component life history and maintenance duration. The application of the model by direct Monte Carlo simulation is illustrated on an oil processing train operating in Arctic offshore. A scheduled preventive maintenance task is considered to cope with the potential reductions in system availability under harsh operating conditions.
\end{abstract}

Keywords: Dynamic weather conditions, failure rate, repair rate, equivalent age, preventive maintenance, availability, Monte Carlo simulation, oil and gas, Arctic offshore.

\section{Acronyms}

$\begin{array}{ll}\text { ALM } & \text { Accelerated Life Model } \\ \text { ALT } & \text { Accelerated Life Test } \\ \text { AR } & \text { Auto-Regressive } \\ \text { ARMA } & \text { Auto-Regressive Moving Average } \\ \text { CM } & \text { Corrective Maintenance } \\ \text { CDF } & \text { Cumulative Distribution Function } \\ \text { MC } & \text { Monte Carlo } \\ \text { MDT } & \text { Mean Total Downtime } \\ \text { MTTF } & \text { Mean Time to Failure } \\ \text { NCS } & \text { Norwegian Continental Shelf } \\ \text { O\&G } & \text { Oil and Gas } \\ \text { PDF } & \text { Probability Density Function } \\ \text { PHM } & \text { Proportional Hazard Model }\end{array}$


PM

RAM

TTF

TTFF

TTR

WCT

WIL

\section{Notation}

$\overline{A(\tau)}$

$A g e_{i}$

$A R(P)$

$D T_{L^{0}}$

$D T_{L^{j}}$

$F_{i}\left(t_{i}^{* \prime}-\right.$

$\left.t^{*} \mid t^{*}\right)$

$f_{L^{j}}(t)$

$F_{L^{j}}(t)$

$L^{j}$

$L_{K}$

$M D T_{i, L^{0}}$

$n_{S}$

K

\section{$R(t)$}

$R_{L_{K}}(\cdot)$

$S_{L^{j}}$

$S_{T}(K)$

$S_{W}(K)$

$t_{0, i}$

$t_{e, K-1}$

$t_{\text {end }}$

$t_{u_{c}}$

$t_{d_{c}}$
Preventive Maintenance

Reliability, Availability, and Maintainability

Time to Failure

Time to First Failure

Time to Repair

Wind Chill Temperature

Weather Intensity Level

System mean availability under dynamic weather conditions over the time interval $[0, \tau]$

Equivalent age of component $i$ prior to $t_{0, i}$, when it has started its current state Auto-regressive process of order $P$

Total downtime in the base area, including active repair time $T T R_{L^{0}}$ and waiting downtime $W D T_{L^{0}}$

Total downtime of a component that undergoes CM actions under static weather conditions with WIL $L^{j}$, including active repair time $T T R_{L^{j}}$ and waiting downtime $W D T_{L^{j}}=W D T_{L^{0}}$

Failure probability of component $i$ at $t_{i}^{* \prime}$, conditional on that it has survived until $t^{*}$, under dynamic weather conditions

Probability density function of a component TTF operating under static weather conditions at the WIL $L^{j}$

Failure distribution of a component operating under static weather conditions at WIL $L^{j}$, with $L^{0}$ corresponding to normal-climate conditions

Weather intensity level $j ; j=0,1, \ldots, J$. The whole range of the weather conditions is divided into $J+1$ levels, with $L^{0}$ being he normal weather intensity level.

Weather intensity level at any time $t$ belonging to the $K$ th interval $\left[t_{K-1}^{\prime}, t_{K}^{\prime}\right.$ ) partitioning the time horizon, such that $L_{K} \in\left\{L^{j}\right\} ; j=0, \ldots, J$

Mean total downtime in the base area for component $i$

Total number of simulation runs

Index of time intervals $\left[t_{K-1}^{\prime}, t_{K}^{\prime}\right) ; K=1, \ldots, N ; t_{0}^{\prime}=0$, partitioning the time horizon, during which the weather conditions remain unchanged at an intensity level of $L_{K}$. In this study, the time interval length is taken to be equal to a day. Component reliability at time $t \in\left[t_{K-1}^{\prime}, t_{K}^{\prime}\right)$

Reliability of a component operating under static weather conditions at WIL $L^{j}$

State of the system at WIL $L^{j}, j=0, \ldots, J ; S_{L^{j}}=1$ and $S_{L^{j}}=0$ refer to the functioning and faulty states, respectively.

Seasonality term of the min temperature time-series at the $K$ th day

Seasonality term of the wind speed time-series at the $K$ th day

Time at which component $i$ either has started its current functioning state or it has entered the current faulty state

Time equivalent to $t_{K-1}^{\prime}$

Time horizon and operation end time, which is equal to $t_{N}^{\prime}$

Time point at which the component fails during its $c$ th life cycle

Time point at which the component is restored back to its functioning state and starts its $(c+1)$ th life cycle 


\begin{tabular}{|c|c|}
\hline$T E M P(K)$ & m temperature at the $K$ th day, in ${ }^{\circ} \mathrm{C}$ \\
\hline$T T F_{L^{j}}$ & $\begin{array}{l}\text { TTF of a component operating under static weather conditions at the WIL } L^{j} \text {, } \\
j=0, \ldots, J \text { with } j=0 \text { being referred to the normal weather conditions }\end{array}$ \\
\hline$T T R_{L^{j}}$ & $\begin{array}{l}\text { TTR of a component operating under static weather conditions at the WIL } L^{j} \text {, } \\
j=0, \ldots, J \text { with } j=0 \text { being referred to the normal weather conditions }\end{array}$ \\
\hline uptime $_{c}$ & $\begin{array}{l}\text { Length of the time interval }\left[t_{d_{c-1}}, t_{u_{c}}\right] \text { during which a component has been } \\
\text { functioning during its } c \text { th life cycle }\end{array}$ \\
\hline uptime $_{e, c}$ & Equivalent time of uptime $_{c}$ \\
\hline$W C T(K)$ & Wind chill temperature at plant location at $t \in\left[t_{K-1}^{\prime}, t_{K}^{\prime}\right)$ \\
\hline$W D T_{L^{0}}$ & $\begin{array}{l}\text { Waiting downtime before commencing CM tasks in the base area, which } \\
\text { includes the time required to shut down the unit, issue the work orders, wait } \\
\text { for the spare parts, and start up the unit after repair. }\end{array}$ \\
\hline$W E$ & $\begin{array}{l}\text { Veather element referring to either minimum daily air temperature or } \\
\text { taximum daily wind speed, i.e., } W E \in\left\{T E M P, W I N D^{\prime}\right\}\end{array}$ \\
\hline$W I N D(K)$ & Maximum wind speed during $K$ in $\mathrm{km} / \mathrm{hr}$ \\
\hline$W \operatorname{IND}^{\prime}(t)$ & 3ox-Cox transformed wind speed at the $K$ th day \\
\hline$X$ & $\begin{array}{l}\text { he factor by which the weather-dependent factor } \delta_{L_{K}, i} \text { changes due to } \\
\text { lodifications to plant design }\end{array}$ \\
\hline$Y$ & $\begin{array}{l}\text { he factor by which the weather-dependent factor } \varepsilon_{L_{K}, i} \text { changes due to } \\
\text { odifications to the comfort of maintenance crew, or modifications to the plant } \\
\text { esign resulting in changes in component active repair time }\end{array}$ \\
\hline$\beta_{L^{0}}$ & $\begin{array}{l}\text { eibull shape parameter, estimated using the life data collected in the base } \\
\text { ea (i.e., normal weather conditions) }\end{array}$ \\
\hline $\begin{array}{l}\Delta t_{K}^{\prime}=t_{K}^{\prime}- \\
t_{K-1}^{\prime}\end{array}$ & $\begin{array}{l}\text { Length of the time interval }\left[t_{K-1}^{\prime}, t_{K}^{\prime}\right) ; K=1, \ldots, N \text {, partitioning the time } \\
\text { horizon; during each time interval the weather conditions are assumed constant }\end{array}$ \\
\hline$\delta_{L^{j}}$ & $\begin{array}{l}\text { Weather-dependent multiplicative factor corresponding to the WIL } L^{j}, j= \\
0, \ldots, J \text { with } \delta_{L^{0}}=1 \text {, which accounts for the reductions in TTFs. }\end{array}$ \\
\hline$\delta_{L_{K}}$ & $\begin{array}{l}\text { Weather-dependent multiplicative factor corresponding to the WIL } L_{K}=L^{j} \text {, } \\
j=0, \ldots, J \text { at the } K \text { th time interval } K=1, \ldots N \text {, which accounts for the } \\
\text { reductions in TTFs }\end{array}$ \\
\hline$\varepsilon_{L^{j}}$ & $\begin{array}{l}\text { Weather-dependent multiplicative factor corresponding to the WIL } L^{j}, j= \\
0, \ldots, J \text { at the } K \text { th time interval } K=1, \ldots N \text {, which accounts for the rises in } \\
\text { TTRs }\end{array}$ \\
\hline$\varepsilon_{L_{K}}$ & $\begin{array}{l}\text { Weather-dependent multiplicative factor corresponding to the WIL } L_{K}=L^{j} \text {, } \\
j=0, \ldots, J \text { at the } K \text { th time interval } K=1, \ldots N \text {, which accounts for the rises in } \\
\text { TTRs }\end{array}$ \\
\hline$\varepsilon_{L^{j}}^{*}$ & $\begin{array}{l}\text { Modified weather-dependent multiplicative factor corresponding to the WIL } \\
\text { of } L^{j}, j=0, \ldots, J \text {, which accounts for the rises in total downtimes }\end{array}$ \\
\hline$\varepsilon_{L_{K}}^{*}$ & $\begin{array}{l}\text { Modified weather-dependent multiplicative factor corresponding to the WIL } \\
\text { of } L_{K}=L^{j}, j=0, \ldots, J \text {, which accounts for the rises in total downtimes }\end{array}$ \\
\hline$\zeta_{T}$ & $\begin{array}{l}\text { Realisation of the final residuals of temperature time-series data, sampled from } \\
\text { the standard normal distribution }\end{array}$ \\
\hline$\zeta_{W}$ & $\begin{array}{l}\text { Realisation of the final residuals of wind speed time-series data, sampled from } \\
\text { standard normal distribution }\end{array}$ \\
\hline$\lambda_{L^{j}}(t)$ & $\begin{array}{l}\text { Hazard rate of the component operating under static weather conditions at the } \\
\text { WIL } L^{j}, j=0, \ldots, J \text {, with } j=0 \text { being referred to the normal weather } \\
\text { conditions }\end{array}$ \\
\hline$\lambda_{L_{K}}(t)$ & Hazard rate of a component at $t \in\left[t_{K-1}^{\prime}, t_{K}^{\prime}\right)$ \\
\hline
\end{tabular}




$\begin{array}{ll}\lambda(t) & \begin{array}{l}\text { Component hazard rate at } t \in\left[t_{K-1}^{\prime}, t_{K}^{\prime}\right) \text { considering operation under dynamic } \\ \text { weather conditions }\end{array} \\ & \text { Repair rate of a component, considering the CM tasks are performed under } \\ & \text { static weather conditions at the WIL } L^{j}, j=0, \ldots, J \text {, with } j=0 \text { being referred } \\ & \text { to the normal weather conditions } \\ & \text { Component repair rate at } t \in\left[t_{K-1}^{\prime}, t_{K}^{\prime}\right) \\ \mu_{L_{K}}(\cdot) & \text { Component repair rate at time } t \in\left[t_{K-1}^{\prime}, t_{K}^{\prime}\right) \text {, considering the CM tasks are } \\ \mu(t) & \text { performed under dynamic weather conditions } \\ \sigma_{T}(K) & \text { Seasonally timed-dependent standard deviation of the temperature data at the } \\ & K \text { th day } \\ \sigma_{W}(K) & \text { Seasonally timed-dependent standard deviation of the temperature data at the } \\ & K \text { th day } \\ \tau_{P M} & \text { PM interval in years } \\ \psi_{T}(K) & \text { Residual process of the air temperature time-series at the } K \text { th day } \\ \psi_{W}(K) & \text { Residual process of the wind speed time-series at the } K \text { th day } \\ \omega & \text { Box-Cox transformation coefficient } \\ \epsilon_{T} & \text { Final residuals of temperature time-series, which follow a standard normal } \\ & \text { distribution } \\ \epsilon_{W} & \text { Final residuals of wind speed time-series, which follow a standard normal } \\ & \text { distribution }\end{array}$

\section{Introduction}

Reliability, Availability and Maintainability (RAM) analyses are at the basis of informed maintenance decision-making and, thus, are essential for the management of profitable and safe production plants and assets. In this work, we are interested in Arctic Oil and Gas (O\&G) plants, where the extreme weather conditions not only demand addressing peculiar technical issues in design and construction, but also greatly challenge maintenance engineering, as the harsh environment renders it difficult to perform labour actions, with consequent large downtimes and business interruptions [1-4] and affects the degradation processes, and therefore the reliability, of components and systems. For these reasons, it is fundamental that RAM analyses of Arctic O\&G plants give due account to the influence of the environmental and operational parameters (e.g., fluid properties for engines, turbines, compressors, etc.) on the Time to Failure (TTF) [5] and Time to Repair (TTR) distributions of components and systems.

To do this, different approaches have been proposed in the literature. Among them, the Accelerated Life Models (ALMs) and the Proportional Hazard Models (PHMs) have proven effective [6]. Both approaches consider a baseline probability model describing the evolution of the degradation process in normal conditions and, then, introduce covariates on the degradation process to account for conditioning aspects of the component life, environment, loading, etc. The difference between ALMs and PHMs lies in the modelling of the dependence of the aging process on the covariates. While in PHMs the effects of covariates are modelled as multiplicative factors in the failure rates, ALMs model explicitly the operating environment impacts on TTFs [5, 7-12].

PHMs have been applied to the specific context of Arctic O\&G operation $[13,14]$ to characterise the impacts of influencing factors such as human factors, logistic delays and severe weather conditions on equipment reliability, maintainability and spare part provision plans. Such studies however, do not account for the dynamicity of operating conditions. More generally, advanced PHMs have been proposed [15-19] to analyse the hazard rate behaviour in the presence 
of dynamically evolving covariates, such as the weather conditions, including changes in wind speed, occurrence of storms and lightning events, etc. [20-22]. Although these approaches seem attractive for their potential of providing more precise estimates of RAM, their application to practical Arctic offshore O\&G case studies is still prevented from the lack of reliability and operating data for proper setting of the RAM models. In fact, although O\&G facilities have been expanding into remote, severe-weather Arctic offshore regions for several years, detailed maintenance data on O\&G facilities are available only in relation to normal-climate regions [23]. These data cannot be used for RAM analyses of facilities in the Arctic area, as they are not representative of the effects of severe weather conditions, and their seasonality. Furthermore, the relationship between the hazard rate of components, such as pumps, turbines, pressure vessels, and valves, their operational parameters (e.g., fluid properties, fluid temperature, pressure, etc.) and the weather conditions typical of the Arctic region, such as very low temperatures, icing severity, etc. is unknown.

The situation has led to the development of pragmatic maintenance models fed by either qualitative information retrievable from experts or physical knowledge coming from the scientific literature. For example, qualitative information is used to directly modify the Mean Time to Failure (MTTF) of components for electrical production plant components [24, 25] and of mechanical equipment units operating in an Arctic offshore oil processing train [26]. These works generalize the practical approach proposed in [27] by putting emphasis on the treatment of uncertainty and imprecision related to the information sources used to estimate the parameters of the models, but they do not account for the accumulated effects of the covariates on the equipment failure behaviour.

To overcome this limitation, the concept of effective age, also called virtual age, has been introduced in [28] and adopted by several works (e.g., [10, 29, 30]). The underlying idea is that, by analogy with what happens with human beings, two similar components (i.e., of the same production lot) with the same calendar age can have different performance if they operate in different environmental conditions or at different stress and load levels. This suggests modelling the aging process of a component in terms of its effective age, which may evolve faster or slower than chronological time whether in adverse or favourable working conditions.

The aim of the present work is to develop a virtual age model, which describes the impacts of the time-varying and stressing operating conditions (i.e., dynamic weather conditions) on both TTF and TTR, and to analyse the availability of an O\&G system in the Arctic environment. Baseline failure and maintenance models are tuned with the data available for normal environmental conditions; according to the approach suggested in [27], these parameters are then modified by weather-dependent multiplicative factors to take into account the accumulated effects of the dynamic weather conditions. Note that the term "dynamic" has been used to stress the difference between the present study and previous works of the literature (e.g., [14, 26, 31]), which have investigated the system reliability and production performance in time-independent operating conditions (e.g., static weather conditions). Air temperature and wind speeds are considered the two elements of the weather conditions that most influence the components failure behaviour and the maintenance action performance and for this reason, they are forecasted for the whole operation period using long-term seasonal auto-regressive (AR) time-series. To cope with the lack of data, the weather-dependent multiplicative factors are assumed to be elicited from experts. The developed model in this study is derived in analogy with Accelerated Life 
Testing (ALT) models and the study done by XiaoFei and Min [30] that propose a Markov additive process to describe a hazard rate evolution in terms of effective age, but with some original contributions. Namely, the model is specialized for the impacts of extreme weather conditions on equipment failure and repair rates and eventually system reliability and availability performance. Moreover, a direct Monte Carlo (MC) simulation approach is adapted to analyse system availability performance, while accounting for virtual age of system components and maintenance tasks. The model also is used to analyse the impact of calendar-based scheduled Preventive Maintenance (PM) tasks on plant availability. Additionally, the alternative assumptions of minimal and perfect repairs in RAM analyses are investigated. The sensitivity of system availability to the changes in multiplicative weather-dependent factors is investigated, as well.

The rest of the paper is organised as follows. Section 2 describes the model and its underlying concepts and assumptions, as well as the equipment reliability and maintainability models under dynamic weather conditions together with the concept of perfect and minimal repairs. To illustrate the application of the developed model, a case study in Arctic offshore O\&G operations is presented in Section 3, where an approach is developed for estimating the weatherdependent multiplicative factors, which enter the model of system availability performance under dynamic weather conditions. Additionally, the availability performance of the system under a calendar-based scheduled PM task is analysed and its sensitivity to weather-dependent factors are discussed. Conclusions are drawn in Section 4.

\section{Model description}

Consider a multi-component system with binary components (i.e., having two states: State 1 functioning - and State 0 - faulty), which undergo Corrective Maintenance (CM) tasks, upon failure and scheduled PM actions, periodically. The system operates in an Arctic location with dynamic weather conditions, whose harshness is summarized into a Weather Intensity Level (WIL), $L^{j}, j=0, \ldots, J$. For instance, one may divide the WILs into three levels of normal $\left(L^{0}\right)$, cold $\left(L^{1}\right)$, and severe $\left(L^{2}\right)$ weather conditions, respectively, as shown in Figure 1.

In this work, we are interested in estimating the multi-component system availability over time, giving due account to the effect of dynamically evolving weather conditions on component TTR and TTF. For this, the system time horizon $\left[0, t_{\text {end }}\right]$ is first divided into $K$ intervals $\left[t_{K-1}^{\prime}, t_{K}^{\prime}\right)$ with length $\Delta t_{K}^{\prime}=t_{K}^{\prime}-t_{K-1}^{\prime} ; K=1, \ldots, N$, for $t_{0}^{\prime}=0$ and $t_{N}^{\prime}=t_{\text {end }}$. Then, the following two processes are considered:

- WIL stepwise process: this is a stochastic process, where weather elements, such as wind speed and air temperatures, change randomly over time, although it is assumed that they remain constant during an interval $\left[t_{K-1}^{\prime}, t_{K}^{\prime}\right)$. It should be also noted that the weather conditions may change while components are under repair or functioning.

- The failure and repair processes: without loss of generality, it is assumed that the components are statistically-independent with Weibull-distributed failure times and exponentially-distributed repair times. These assumptions are justified by the following considerations: Weibull distribution is one of the most commonly used lifetime distributions in reliability analysis due to its flexibility in modelling lifetime data with different hazard rate behaviours [32, 33], whereas the exponential distribution is one of 
the simplest and most common repair time distributions used in industrial practice [34]. Note that Weibull distribution for failure behaviour analysis of the components is preferred over exponential distribution. This is because in practice, CM tasks do not completely remove all the degradation from components and thus the failure distribution model should be able to capture the degradation effect of the component over time by considering an increasing failure rate.

Figure 1 represents the behaviour of a binary component in the phase space [35], which evolves the aforementioned dynamic weather conditions in time.

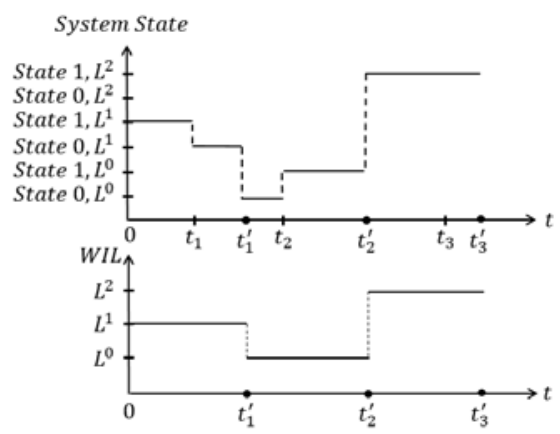

Figure 1. A random-walk example of a two-state single-component system under dynamic WILs

As shown in Figure 1, the component starts at time $t=0$ from WIL of $L 1$ in operating state indicated by $(0,(1, L 1))$. Then, the component fails at time $t_{1}$ and, thus, enters state $\left(t_{1},(0, L 1)\right)$. While the system is under repair, WIL changes to $L 0$ at $t_{1}^{\prime}$. Therefore, the crew performs the rest of the CM under normal weather conditions until time $t_{2}$, when the component is brought back to the functioning state, i.e., $\left(t_{2},(1, L 0)\right)$. Finally, the component continues working while the WIL changes to $L 2$ at $t_{2}^{\prime}$ and remains at this level until $t_{3}^{\prime}$.

\subsection{Modelling hazard rate under dynamic weather conditions}

In this Section, we propose a model to take account of the effect of the time-varying environmental conditions on the failure behaviour of $O \& G$ components operating in Arctic areas. The model is derived from the step-stress ALT approach [36, 37], in which the acceleration of the degradation process is obtained by the exposition of the test units to operating conditions severer than normal. By analogy with the ALT models, WILs are here considered as the stress levels applied to the components: harsher weather conditions put the system under severer stresses, and reduce component TTFs.

Consider a location with a constant WIL of $L^{j}, j>0$. According to the approach suggested by Department of Defense [27], the reduction in component TTF is pragmatically modelled by multiplying the baseline TTF, $T T F_{L^{0}}$, which is the TTF of the component operating in a normal-climate region (i.e., base area), by a parameter $\delta_{L^{j}} \in(0,1]$ dependent on the WIL of $L^{j}$ :

$$
T T F_{L^{j}}=\delta_{L^{j}} T T F_{L^{0}}
$$

where $\delta_{L^{j}}$ is constant as WIL remains unchanged.

In this work, we consider aging components, whose failure times obey the Weibull Cumulative Distribution Function (CDF): 


$$
F_{L^{0}}(t)=1-\mathrm{e}^{\left(\frac{t}{\eta_{L^{0}}}\right)^{\beta_{L^{0}}}}
$$

where $\eta_{L^{0}}$ is the scale parameter and $\beta_{L^{0}}$ is the shape parameter for normal conditions, estimated using the data gathered in the base area.

Application of simple rules to derive the CDF of a random variable, $T T F_{L^{j}}$, which is linearly dependent on a random variable $\left(T T F_{L^{0}}\right)$, as given in Equation (1) with known distribution $F_{L^{0}}\left(t_{0}\right)$, given by Equation (2) yields [36, 37]:

$$
F_{L^{j}}(t)=F_{L^{0}}\left(\frac{t}{\delta_{L^{0}}}\right)=1-\mathrm{e}^{\left(\frac{t}{\delta_{L^{j}} L_{L^{0}}}\right)^{\beta} L^{0}}
$$

The hazard rate function of the component under the WIL of $L_{K}$ can be easily derived from Equation (3) [38],

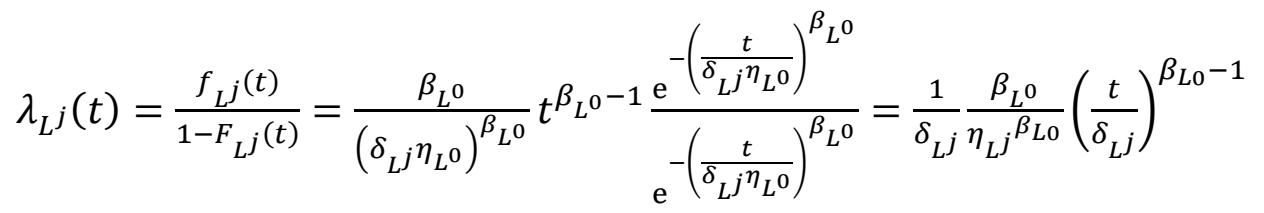

or

$$
\lambda_{L^{j}}(t)=\frac{1}{\delta_{L^{j}}} \lambda_{L^{0}}\left(\frac{t}{\delta_{L^{j}}}\right)
$$

where $f_{L^{j}}(t)$ is the Probability Density Function (PDF) of $T T F_{L^{j}}$, whereas $\lambda_{L^{0}}\left(t / \delta_{L^{j}}\right)$ is the component hazard rate under normal operating conditions at time $t / \delta_{L^{j}}$, which represents the equivalent time of the equipment. This introduces the concept of effective age, i.e., the age of a component which has been operating for time $t$ under WIL of $L^{j}$, is equivalent to $t / \delta_{L^{j}}$, which is the age of the component operating under normal weather conditions. In practice, at an arbitrary time $\tau$ the hazard rate of a component operating under WIL $L^{j}$ equals the base hazard rate at $\tau / \delta_{L^{j}}$, which is the time equivalent to $\tau$, multiplied by $1 / \delta_{L^{j}}$ (Figure 2 ).

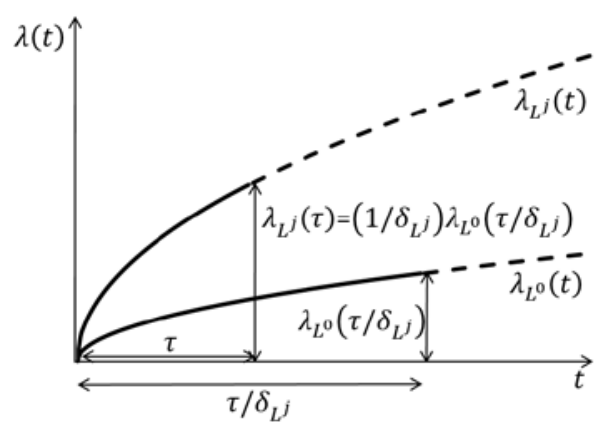

Figure 2. The relationship between hazard rates in the base area and under the WIL $L^{j}$

Although Equation (4) explicitly indicates the dependence of the component hazard rate upon the weather conditions, it assumes that these conditions remain constant at WIL $L^{j}$ over time, i.e., static weather conditions, which is equivalent to single stress ALM. Thus, Equation (4) cannot be directly applied to the case of dynamically evolving weather conditions; rather it needs being extended to encode WIL changing over time.

To do this, we propose a computational approach in which the evolution of the reliability of a component under dynamic weather conditions in each time interval $\left[t_{K-1}^{\prime}, t_{K}^{\prime}\right)$ depends on 
the equivalent age updated at the beginning of the interval. That is, the component reliability and hazard rate at $t \in\left[t_{K-1}^{\prime}, t_{K}^{\prime}\right)$ with WIL $L_{K} \in\left\{L^{j}\right\} ; j=0, \ldots, J$, can be respectively given by [37],

$$
R(t)=R_{L_{K}}\left(t-t_{K-1}^{\prime}+t_{e, K-1}\right) \quad \text { if } t \in\left[t_{K-1}^{\prime}, t_{K}^{\prime}\right) ;(K=1,2, \ldots, N)
$$

$$
\lambda(t)=\lambda_{L_{K}}\left(t-t_{K-1}^{\prime}+t_{e, K-1}\right) \quad \text { if } \quad t \in\left[t_{K-1}^{\prime}, t_{K}^{\prime}\right) ;(K=1,2, \ldots, N)
$$

(6)

where $t_{e, K-1}$ is the time equivalent to $t_{K-1}^{\prime}$ satisfying the system of equations:

$$
\left\{\begin{array}{c}
R_{L_{2}}\left(t_{e, 1}\right)=R_{L_{1}}\left(t_{1}^{\prime}\right) \\
\ldots \\
R_{L_{K}}\left(t_{e, K-1}\right)=R_{L_{K-1}}\left(t_{K-1}^{\prime}-t_{K-2}^{\prime}+t_{e, K-2}\right)
\end{array} ;(K=2,3, \ldots, N)\right.
$$

with $t_{0}^{\prime}=t_{e, 0}=0$.

For a Weibull failure distribution, the sets of equalities in Equation (7) can be successively solved at the end of every time bin for $t_{e, K-1}, K=2,3, \ldots, N$ by using Equation (3). For example, assume that the component starts in normal weather conditions, (i.e., $L_{1}=L^{0}$ ), and survives the first time channel, upon which there is a sharp change in the weather conditions from $L_{1}=L^{0}$ to $L_{2}=L^{2}$ (see Figure 3). Thus, using Equation (7) we get:

$$
R_{\mathrm{L}_{2}}\left(t_{e, 1}\right)=R_{L_{1}}\left(t_{1}^{\prime}\right) \rightarrow \mathrm{e}^{-\left(\frac{t_{e, 1}}{\delta_{L^{2} L^{0}}}\right)^{\beta} L^{0}}=\mathrm{e}^{-\left(\frac{t_{1}^{\prime}}{\delta_{L^{0}} \eta^{0}}\right)^{\beta}} \rightarrow t_{e, 1}=\delta_{L^{2}} \frac{t_{1}^{\prime}}{\delta_{L^{0}}}
$$

where $\delta_{L^{0}}=1$, is the multiplicative weather-dependent factor corresponding to normal weather conditions within the first time channel (i.e., $L_{1}=L^{0}$ ), whereas $\delta_{L_{2}}$ is the factor related to the WIL within the second time channel, i.e., $L_{2}=L^{2}$. In other words, the amount of life burnt in the first time channel at WIL $L^{2}$ is equivalent to a smaller time if the component were at WIL $L^{2}$ because $\delta_{L_{2}} \in(0,1)$.

Repeating the application of Equation (7) to the next time channels, one finally gets:

$$
t_{e, K-1}=\delta_{L_{K}} \sum_{k=2}^{K} \frac{\Delta t_{k-1}^{\prime}}{\delta_{L_{k-1}}} \quad \text { if } \quad t \in\left[t_{K-1}^{\prime}, t_{K}^{\prime}\right) ;(K=2,3, \ldots, N)
$$

where $\Delta t_{k-1}^{\prime}=t_{k-1}^{\prime}-t_{k-2}^{\prime} ; k=2,3, \ldots, K$ and $t_{0}^{\prime}=0$.

Figure 3 shows the updating of the equivalent age for a component operating under dynamic weather conditions with three WILs of $\left\{L^{j}\right\}=\left\{L^{0}, L^{1}, L^{2}\right\}$. It can be seen that the functional form of the hazard rate at $t \in\left[t_{K-1}^{\prime}, t_{K}^{\prime}\right)$ is determined by $\lambda_{L_{K}}(\cdot)$, which is computed at an equivalent time, $t-t_{K-1}^{\prime}+t_{e, K-1}$.

Finally, Equations (5) and (6) can be rewritten for a component with Weibull-distributed TTFs using Equation (8). Thus, the reliability, $R(t)$, and the hazard rate, $\lambda(t)$, of a component at time $t \in\left[t_{K-1}^{\prime}, t_{K}^{\prime}\right)$ on the condition that it has been operating under dynamic WILs of $L_{k} ; k=$ $1,2, \ldots, K$, are given by, respectively: 
$R(t)=\exp \left[-\left(\frac{\frac{t-t_{K-1}^{\prime}}{\delta_{L_{K}}}+\sum_{k=1}^{K} \frac{\Delta t_{k-1}^{\prime}}{\delta_{L_{k-1}}}}{\eta_{L^{0}}}\right)^{\beta_{L^{0}}}\right] \quad$ if $t \in\left[t_{K-1}^{\prime}, t_{K}^{\prime}\right) ;(K=1,2, \ldots, N)$

$\lambda(t)=\frac{\beta_{L^{0}}}{\left(\delta_{L_{K}} \eta_{L^{0}}\right)^{\beta} L^{0}}\left(t-t_{K-1}^{\prime}+\delta_{L_{K}} \sum_{k=1}^{K} \frac{\Delta t_{k-1}^{\prime}}{\delta_{L_{k-1}}}\right)^{\beta_{L 0^{-}}-1}$ if $t \in\left[t_{K-1}^{\prime}, t_{K}^{\prime}\right) ;(K=1,2, \ldots, N)$

with $\Delta t_{0}^{\prime}=0$.

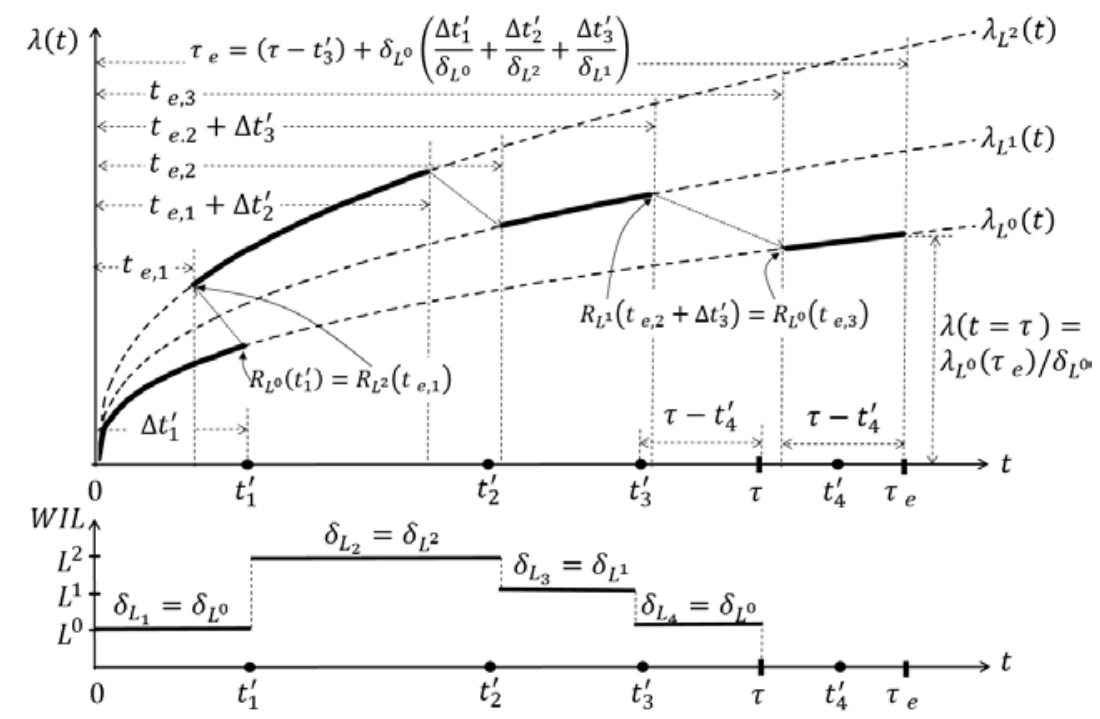

Figure 3. Illustration of a piecewise Weibull hazard rate under dynamic weather conditions

\subsection{Modelling repair rate under dynamic weather conditions}

Upon component failure, the total downtime includes the waiting downtimes, WDT, such as the time required to shut down the unit, issue the work orders, wait for the spare parts and start up after repair, as well as the active repair time, TTR, i.e., the labour time required to repair the failed component. If the sum of all the waiting downtimes in the base area is denoted by $W D T_{L^{0}}$, then the total downtime of the unit in the base area, $D T_{L^{0}}$, can be expressed by,

$$
D T_{L^{0}}=W D T_{L^{0}}+T T R_{L^{0}}
$$

where $T T R_{L^{0}}$ is the TTR of the component operating in the base area, i.e., under normal weather conditions.

The harsh weather conditions can result in extended downtimes owing to extended TTR, only. That is, we assume that the waiting downtimes are independent of the operating conditions. The same approach followed for the hazard rate modelling can be adopted for the estimation of the hazard rate of a component, taking account of dynamic weather conditions. First, consider a case where the CM tasks are taking place under static weather conditions, whose level is $L^{j}$. We can, then, express the TTR of the component operating under WIL $L^{j}$ as

$$
T T R_{L^{j}}=\varepsilon_{L^{j}} T T R_{L^{0}}
$$


where $\varepsilon_{L^{j}} \geq 1$ is a weather-dependent multiplicative factor that is constant while WIL remains unchanged. By substituting Equation (12) into (11), we get the total downtime of a component operating under WIL $L^{j}$ :

$$
D T_{L^{j}}=W D T_{L^{0}}+\varepsilon_{L^{j}} T T R_{L^{0}}
$$

To simplify Equation (13) and make it similar to Equation (1), we can set:

$$
D T_{L^{j}}=\varepsilon_{L^{j}}^{*} D T_{L^{0}}
$$

where

$$
\varepsilon_{L^{j}}^{*}=\frac{W D T_{L^{0}}+\varepsilon_{L^{j}}{ }^{T T R_{L^{0}}}}{W D T_{L^{0}}+T T R_{L^{0}}}
$$

Equation (15) modifies the weather-dependent factor, $\varepsilon_{L^{j}}$, by including the overall waiting downtimes.

By following the same approach used for the hazard rate modelling, and by adopting an exponential distribution function for component maintainability (i.e., setting the shape factor equal to 1 ), the repair rate of a component under WIL $L^{j}$ can be modelled as:

$$
\mu_{L^{j}}=\frac{1}{\varepsilon_{L^{j}}^{*}} \mu_{L^{0}}
$$

where $\mu_{L^{0}}$ is the constant repair rate of the component, which is the inverse of the mean total downtime $M D T_{L^{0}}$, estimated using the operational data gathered in the base area. Such repair rate includes active repair time and waiting downtimes.

To model the maintainability of a component under dynamic weather conditions, the equalities in Equation (7) can be solved for $t_{e, K-1} ; K=2,3, \ldots, N$ using Equation (16). Thus,

$$
t_{e, K-1}=\varepsilon_{L_{K}}^{*} \sum_{k=2}^{K} \frac{\Delta t_{k-1}^{\prime}}{\varepsilon_{k-1}^{*}} \quad \text { if } t \in\left[t_{K-1}^{\prime}, t_{K}^{\prime}\right) ;(K=2,3, \ldots, N)
$$

The concepts of equivalent repair time and stepwise repair rate are illustrated in Figure 4. The repair rate of a component only depends on the factor $\varepsilon_{L_{K}}^{*}$, which remains at a constant level of $\mu_{L^{0}} / \varepsilon_{L_{K}}^{*}$ within $\left[t_{K-1}^{\prime}, t_{K}^{\prime}\right.$ ) (see Figure 4 ).

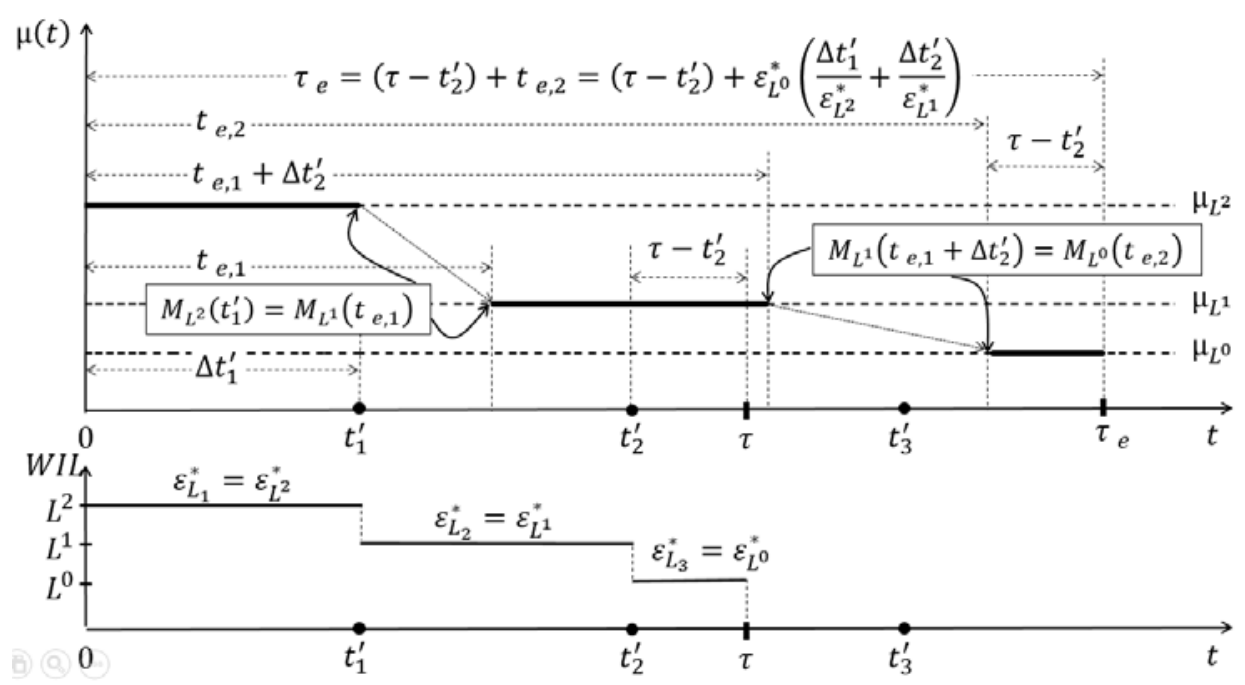

Figure 4. Illustration of a stepwise repair rate under dynamic weather conditions 
The close form of repair rate, $\mu(t)$, and maintainability function, $M(t)$, for a component, whose total downtimes are exponentially distributed, can be obtained by substituting Equation (17) into Equations (5) and (6), respectively:

$$
\begin{aligned}
& M(t)=1-\exp \left[-\left(\frac{t-t_{K-1}^{\prime}}{\varepsilon_{L_{K}}^{*}}+\sum_{k=1}^{K} \frac{\Delta t_{k-1}^{\prime}}{\varepsilon_{L_{k-1}}^{*}}\right) \mu_{L^{0}}\right] \text { if } t \in\left[t_{K-1}^{\prime}, t_{K}^{\prime}\right) ;(K=1,2, \ldots, N) \\
& \mu(t)=\frac{1}{\varepsilon_{L_{K}}^{*}} \mu_{L^{0}} \text { if } t \in\left[t_{K-1}^{\prime}, t_{K}^{\prime}\right) ;(K=1,2, \ldots, N)
\end{aligned}
$$

with $\Delta t_{0}^{\prime}=0$.

\subsection{Perfect and minimal repair assumption}

The reliability of a component modelled by Equation (9) assumes that the initial component age is zero. In repairable systems, this assumption, also referred to as-good-as-new, entails that the component undergoes a perfect repair after each failure. However, in real practices, CM tasks cannot remove all the degradations that a component has experienced during its life. A more conservative assumption is that of minimal repair, which assumes that although the component is brought back to the functioning state, it preserves all the accumulated degradations that has experienced during its previous life cycles (i.e., as-bad-as-old repair).

In the paradigm shown in the previous section, it is sufficient to set the age of the repaired component equal to its age accumulated before the failure occurrence to include the minimal repair assumption in the reliability estimation of a component.

Consider a component functioning in its $(C+1)$ th cycle of life (i.e., after $C$ consecutive failures), has started its current functioning state at time $t_{0}=t_{d_{C}}$ (Figure 5). During the previous cycle $c$, the component has been functioning from $t_{d_{c-1}}$ to $t_{u_{c}}, c=1,2, \ldots, C$, where $C$ is the number of cycles performed within the component time horizon, prior to the present cycle, $C+$ 1. Thus, the uptime of the component during its $c$ th cycle is given by,

$$
\text { uptime }_{c}=t_{u_{c}}-t_{d_{c-1}}, c=1,2, \ldots, C
$$

with $t_{d_{0}}=0$.

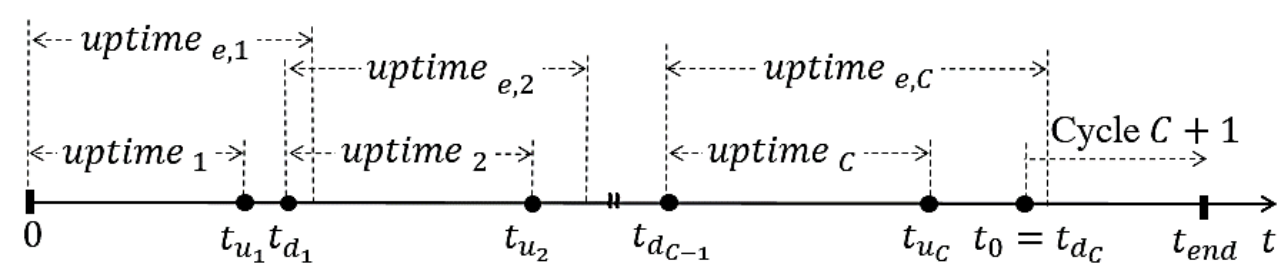

Figure 5. System uptimes and their equivalent times

Equation (20) implies that prior to its current cycle $C+1$, the component has accumulated a total uptime of $\sum_{c=1}^{C}$ uptime $_{c}$. Such uptime needs to be converted into an equivalent time in order to take account of the accumulated effects of the dynamic weather conditions, to which the component has been exposed during its previous $C$ life cycles. To do this, the starting age of the component at the beginning of its current cycle is given by its effective age, $\mathrm{Age}$,

$$
\text { Age }=\sum_{c=1}^{C} \text { uptime }_{e, c}
$$


where uptime $_{e, c}$ is the time equivalent to uptime , $_{c}$ obtained according to the intensity level of current weather conditions. Note that the effective age, Age, cannot be used to estimate the system mean availability, $\bar{A}$, rather we need to use the accumulated uptimes

$$
\bar{A}=\frac{\sum_{c=1}^{C} \text { uptime }_{c}}{t_{\text {end }}}
$$

\subsection{Setting weather intensity levels and weather-dependent factors}

As given by Equations (10) and (19), two sets of model parameters are required to estimate the failure and repair rates of a component operating under dynamic weather conditions:

i. properties of the stochastic failure behaviour such as the shape and scale parameters of failure and repair distributions in base area;

ii. weather-dependent multiplicative factors for every component corresponding to different WILs.

As mentioned before, time-varying PHMs and step-stress ALMs can be adopted to model the influence of the environmental conditions on the component failure and repair behaviour. Statistical techniques [5, 39] can be used to estimate both the baseline parameters as well as the covariate multiplicative factors. However, the robustness of the results of such models strongly rely on the availability of the data on both failure times and the environmental conditions throughout the component life [36], which may not be available for the Arctic offshore O\&G platforms [23]. Alternatively, Naseri and Barabady [26] used an approach based on which the base failure rates, taken from normal-climate regions, are modified by multiplicative factors elicited from experts to account for the extreme weather conditions.

Notice that the underlying assumption of the model developed in this paper to give account to the dynamic weather conditions, derived from ALM, is that the applied stresses due to the extreme environmental conditions do not change the physics of the failure mechanisms (PHAM 2003). This assumption, which practically reflects in constant shape factors, is questionable in the Arctic offshore O\&G applications, where the environmental conditions are combination of different stresses such as environmental (e.g. humidity, temperature) and mechanical (e.g. platform vibration due to crashing the sea ice) stresses. Thus, additional research work must be done to check the validity of the aforementioned hypothesis.

\subsection{Monte Carlo simulation approach}

In this study, a direct MC simulation technique [35, 40-42] is used to estimate the availability of the oil processing plant operating under dynamic Arctic weather conditions. In particular, to include the stochastic behaviour of the weather conditions and their effects on system availability, the MC simulation scheme illustrated in Figure 6 has been developed. 


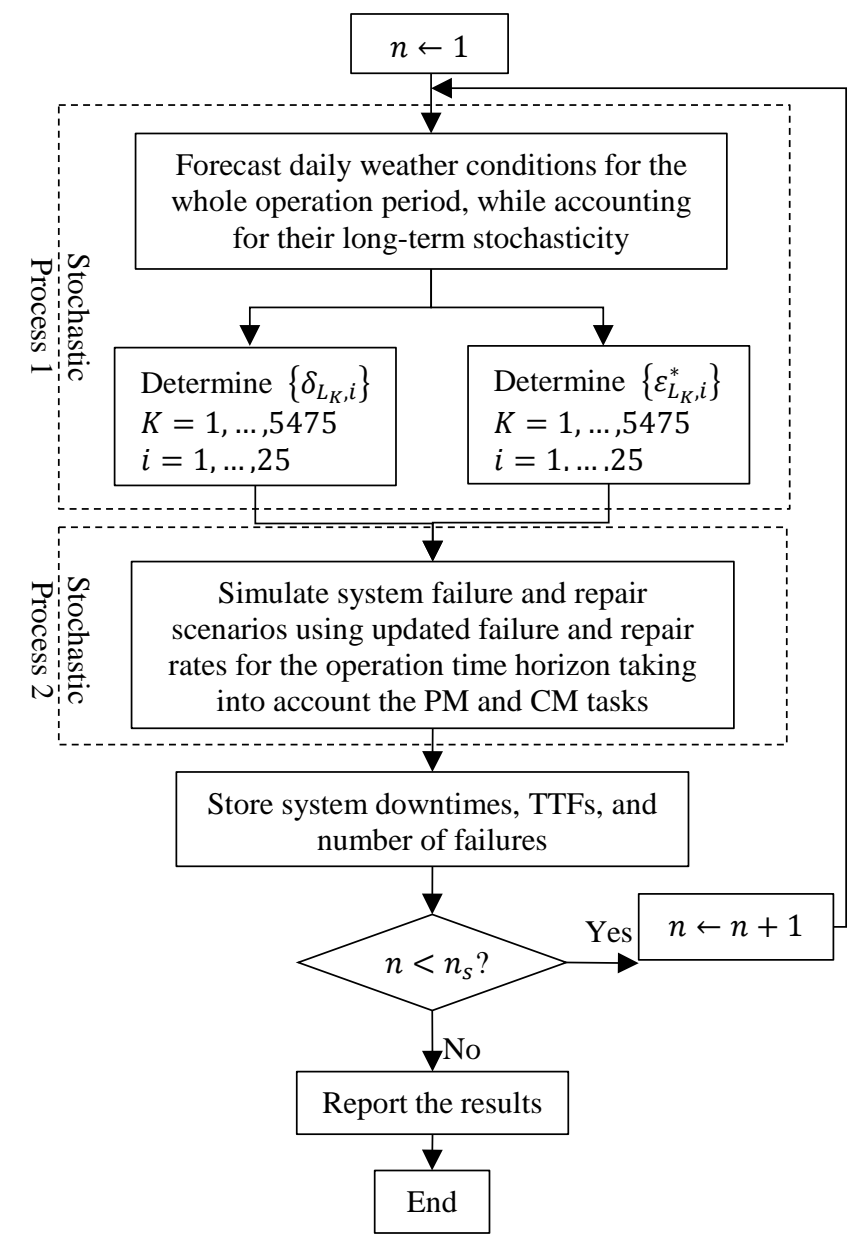

Figure 6. The MC simulation-based algorithm for system availability analysis taking account of dynamic weather conditions

Namely, at the first step, the daily weather conditions are forecasted for the operation time horizon of 15 years. An auto-regressive AR time-series models have been used to account for the stochasticity of the long-term weather conditions. Such models, which are fitted to historical weather data, forecast daily weather conditions using a combination of stochastic and deterministic terms. For this purpose, the developed MC simulation scheme starts with sampling random numbers from standard normal distribution, $N(0,1)$, for the realisations of the stochastic term of auto-regressive AR time-series models. The rest of the model parameters are estimated using historical weather data. A detailed description of the auto-regressive AR time-series models is given in Appendix. Once weather conditions are forecasted, the weather-dependent multiplicative factors, $\delta_{L_{K}}$ and $\varepsilon_{L_{K}}^{*}$ are determined for each component on a daily basis for the operation period, i.e., $K=1, \ldots, 5475$. These values are used to adjust the hazard and repair rate of the system components. A possible approach to quantify $\delta_{L_{K}}$ and $\varepsilon_{L_{K}}^{*}$ is described in the Case Study section.

In the second step of the representation scheme, system failure and repair scenarios are simulated. As time goes on, the system stochastically changes its state, depending on the state of each component and system configuration. The system state is faulty when the simulated scenario leads the system in a configuration of minimal cut set. A CM task is, then, performed to bring the system back to one of its functioning configuration, under the assumption of either minimal or perfect repair. This procedure is followed until the mission time, $t_{\text {end }}$ is reached. In 
correspondence of each system failure and successive repair, the system downtime is recorded and also the number of system failures is collected in each simulation run. The next simulation run, then, starts by forecasting a new set of weather conditions and repeating the aforementioned processes, until a sufficiently large amount of simulation runs, $n_{s}$, are performed. System reliability is estimated using the collected Time to First Failures (TTFFs).

\section{Case study - oil and gas processing plant operating in the Arctic offshore}

This Section illustrates the assessment of the availability of an oil processing train operating under dynamic Arctic weather conditions using the model proposed in this work. In particular, two different locations in the Norwegian Continental Shelf (NCS) are chosen (Figure 7) as the hypothetical locations of an O\&G production plant, of which Ekofisk is in the North (i.e., base area with normal-climate conditions), whereas Hopen Island is located in the Northern Barents Sea (i.e., Arctic region with harsh weather conditions).

Notice that O\&G operations are forbidden on Hopen Island due to strict environmental regulations forbid. Nonetheless, we use this location because its weather data are the only weather data from the Northern Barents Sea publically available, to the author's best knowledge. Certainly, such data are applicable to the regions close to these islands, only. However, the main contribution of the paper, which is on the methodology to gather long-term weather behaviour form such data and embed them into a system availability model, is not affected by this assumption.

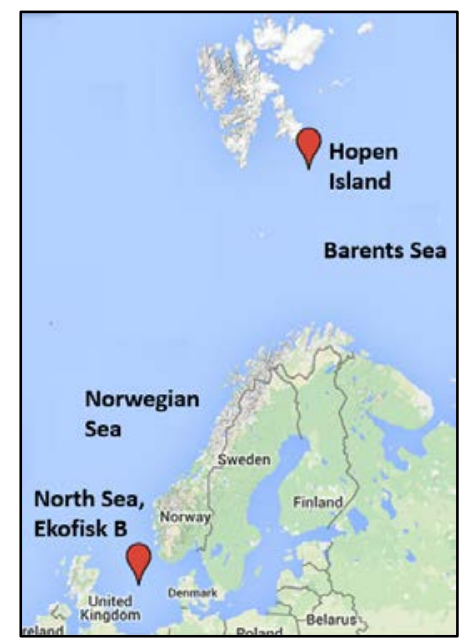

Figure 7. Hypothetical locations of an O\&G production plant in the North and Barents Seas - The location coordinates are taken from http://eklima.met.no

\subsection{System description}

A typical O\&G production plant is illustrated in Figure 8, which is adapted from Naseri and Barabady [26]. The main function of an O\&G production plant is to split the well-stream fluid into water, oil, and natural gas, while removing the impurities. To this aim, the well-stream fluid undergoes a three-stage separation process so that its water, oil, and gas are separated. While the produced water is routed to water treatment facilities, the gas is recompressed in several stages and, then, is routed to gas treatment facilities to be either re-injected into the subsurface formations or exported to the market. Some portion of the produced gas is used as fuel gas, for 
electricity production and for running some equipment units on the platform. Produced oil is pumped into the subsea pipelines after being treated in oil treatment facilities. This study focuses on the availability of the oil processing train, only. The dashed black line in Figure 8 specifies the system boundary. A detailed description of the plant components and their functions are given in [26].

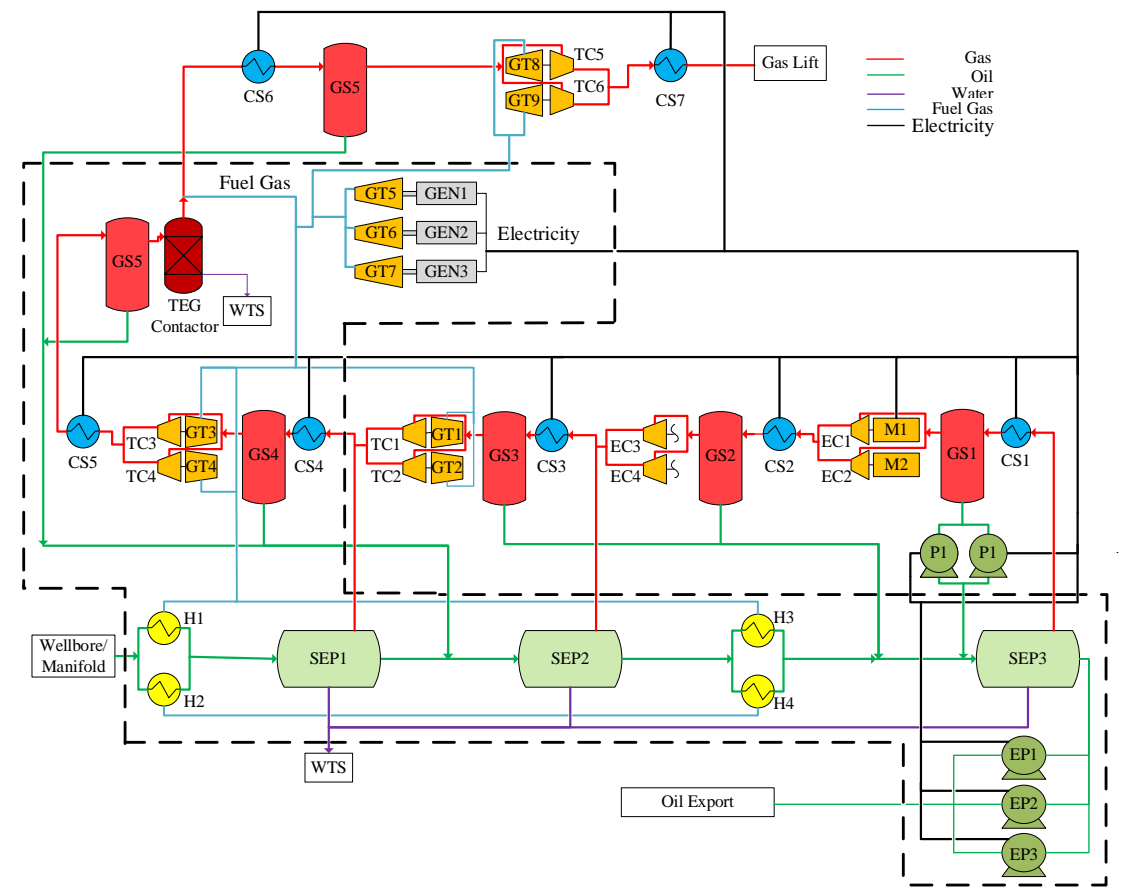

Figure 8. Illustration of a typical O\&G separation plant, adopted from [26]

The identified system consists of 25 binary components. By developing the fault tree corresponding to the top event (i.e., Oil Export failure, as shown in Figure 8), 23 minimal cut sets are identified (Table 1), 8 of which are of order 1, 6 are of order 2, and the 9 are of order 3.

Table 1. System minimal cut sets [26]

\begin{tabular}{|l|ll|}
\hline Order & Minimal cut sets & \\
\hline 1 & SEP1 & SEP2 \\
& SEP3 & TEG \\
& GS4 & GS5 \\
& CS4 & CS5 \\
\hline 2 & H1 \& H2 & H3 \& H4 \\
& GT3 \& GT4 & GT3 \& TC4 \\
& TC3 \& GT4 & TC3 \& TC4 \\
\hline 3 & EP1 \& EP2 \& EP3 & GT5 \& GT6 \& GT7 \\
& GT5 \& GT6 \& GEN3 & GT5 \& GEN2 \& GT7 \\
& GT5 \& GEN2 \& GEN3 & GEN1 \& GT6 \& GT7 \\
& GEN1 \& GT6 \& GEN3 & GEN1 \& GEN2 \& GT7 \\
& GEN1 \& GEN2 \& GEN3 & \\
\hline
\end{tabular}

Failure and repair distribution in the base area can be obtained using available historical data or handbooks where the operations are taking place in normal-weather conditions. For instance, Offshore Reliability Data (OREDA) handbook been established as the de facto state of the art in reliability engineering in the O\&G industry $[23,43]$. OREDA handbook reports the parameters of the hazard rate and average active repair time of a variety of the equipment units installed on offshore O\&G platforms operating in the North and Norwegian Seas, which are 
considered the base area in this study. However, it does not report any data for Arctic offshore regions or the areas with harsh weather conditions.

In this study, since the authors did not have access to detailed historical reliability data and maintenance reports, mean active repair times in the base area are taken from OREDA handbook. Based on the discussion with a number of operation and maintenance engineers, it is assumed that the waiting downtime for a critical failure is 72 hours, which is considered independent of weather conditions. Thus, the Mean Total Downtime (MDT) of a component is conservatively set to the sum of the waiting downtime of 72 hours and the average active repair time, which are reported in Table 2.

The parameters of the Weibull hazard rates for the system components operating under normal weather conditions (i.e., $\eta_{i, L^{0}}$ and $\beta_{i, L^{0}}, i=1,2, \ldots, 25$ ) are presented in Table 2. To respect the intellectual property of the OREDA handbook, in this work we consider shape and scale parameters of the Weibull distributions of the components which are not those of the handbook but similar. In particular, the hazard rate is always considered constant in the OREDA handbook (i.e., $\beta_{i, L^{0}}=1, i=1, \ldots, 25$ ), which corresponds to an exponential distribution of failure time.

Table 2. Failure and repair rate parameters of system components operating in the base area

\begin{tabular}{|l|l|l|l|l|l|}
\hline Component & ID & $\beta_{i, L^{0}}$ & $\begin{array}{l}\eta_{i, L^{0}}, \\
\mathrm{hr}\end{array}$ & $\begin{array}{l}\text { Mean active repair } \\
\text { time (base area), hr }\end{array}$ & $M D T_{i, L^{0}, \mathrm{hr}}$ \\
\hline Separator & SEP1, SEP2, SEP3 & 0.7621 & 22620 & 5.1 & 53.1 \\
\hline Gas scrubber & GS4, GS5 & 0.8685 & 31837 & 5.1 & 53.1 \\
\hline $\begin{array}{l}\text { Triethylene glycol } \\
\text { contactor }\end{array}$ & TEG & 1.2348 & 13082 & 13 & 61 \\
\hline Export pump & EP1, EP2, EP3 & 1.1722 & 5182 & 14 & 62 \\
\hline Crude oil heater & H1, H2, H3, H4 & 1.039 & 10557 & 2.8 & 50.8 \\
\hline Cooling system & CS4, CS5 & 1.2963 & 55535 & 4.2 & 52.2 \\
\hline Turbine-driven generator & GEN1, GEN2, GEN3 & 0.8901 & 15735 & 20 & 68 \\
\hline Gas turbine & GT3, GT4, GT5, GT6, GT7 & 1.4841 & 2615 & 26 & 74 \\
\hline Turbo-compressor & TC3, TC4 & 1.0786 & 9126 & 5.2 & 53.2 \\
\hline
\end{tabular}

\subsection{Weather intensity modelling}

Arctic environmental conditions such as snowstorms, atmospheric and spray icing, winds, low temperatures, sea ice, and polar low pressures are all extreme events that can result in both decreasing reliability and increasing downtimes, which lead to a reduced plant availability. For example, low temperatures can reduce component reliability by increasing the hazard rate of its internal items [44-48]. The combination of low temperatures, wind, and precipitation can reduce crew accessibility to the failed components or increase human error due to the additional difficulties related to falling ice or slippery surfaces. Cold environment can also adversely influence crew performance and their analytical reasoning abilities [49]. In this study, we limit our analysis to the effects of low temperatures and winds on system performance. In particular, based on the discussion with operation and maintenance engineers, it is assumed that wind only influences the performance of maintenance crew and does not affect equipment reliability, whereas temperature can have impacts on both.

\subsubsection{Modelling the effects of low temperature on equipment hazard rate}

The quantification of the temperature-dependent factor $\delta_{L^{j}}$ requires comparing the long-term air temperature profile of the operation location in the Arctic against that of the base area over the 
system time horizon. In this study, we forecast the long-term temperature behaviour over the operation location considering time-series of the minimum daily temperatures.

\subsubsection{Forecasting long-term air temperature}

The empirical PDFs of the historical daily temperature data used in this study are shown in Figure 9. The daily temperature data are taken from the online climate database of the Norwegian Metrological Institute available at http://eklima.met.no. Notice that there are considerable differences in the temperature values in the selected Artic region and base area, although some of the observed temperatures in the Arctic location (i.e., Hopen) are in the range of the temperatures experienced in the base area (i.e., Ekofisk).

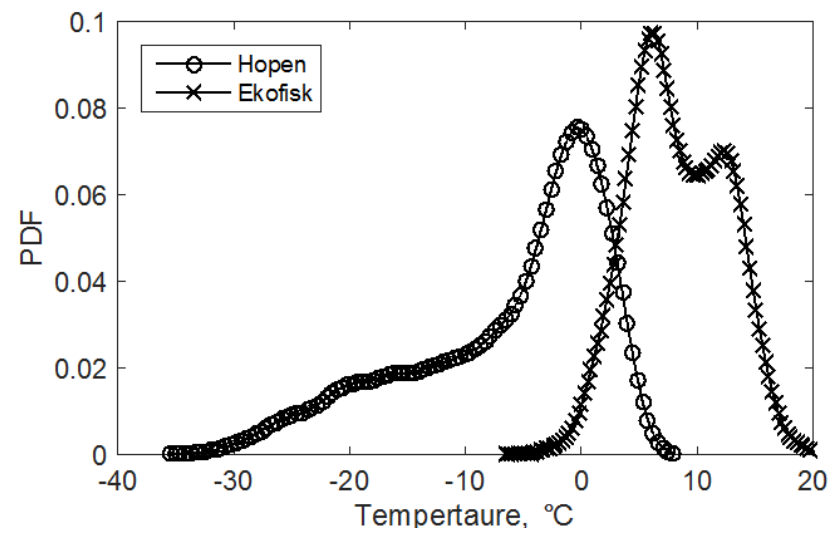

Figure 9. PDF of historical daily temperatures

Figure 10 illustrates a snapshot of Hopen Arctic temperature for a period of 2 years, starting from 01.07.2009 (red line). As can be seen, there is a clear seasonality in the temperature values as well as some random minimum peaks that are especially present during winter seasons. The applied model must be able to represent such properties for long-term forecasts.

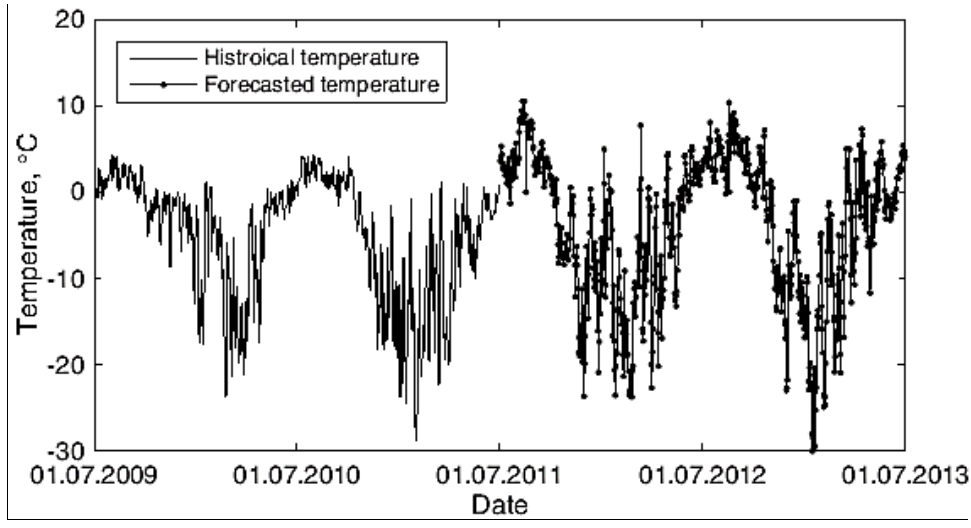

Figure 10. Snapshot of Hopen temperature from 01.07.2009 to 30.06.2011 and forecasted temperature data from 01.07.2011 to 30.06 .2013

In this study, seasonal auto-regressive AR time-series models have been adopted to predict the long-term daily air temperatures (see e.g. [50-54]). Such models describe the daily temperature data using several deterministic and stochastic terms generating the mean and residual processes, respectively. The deterministic term includes the seasonality term (i.e., linear and cyclic trends) as well as the AR process, whereas the stochastic term consists of a zero-mean and temporally independent standard normal random process and a seasonally time-dependent standard deviation function. Such terms can be estimated from observed data through a step-by- 
step decomposition process. A seasonal AR time-series to model the minimum daily air temperatures is given by $[50,52]$ :

$$
\operatorname{TEMP}(K)=S_{T}(K)+\sum_{p=1}^{P} \alpha_{p}\left[T E M P(K-p)-S_{T}(K-p)\right]+\sigma_{T}(K) \epsilon_{T}
$$

where $\operatorname{TEMP}(K)$ is the minimum daily air temperature in ${ }^{\circ} \mathrm{C}, S_{T}(K)$ is the seasonality term, $\alpha_{p}, p=1, \ldots P$ is the coefficient of $A R(P)$ process, $\sigma_{T}(K)$ is the time-dependent standard deviation, and $\epsilon_{T}$ is the standard normal random process. The detailed approach to model and forecast air temperatures as well as the estimated model parameters are given in the Appendix.

Once different terms of the seasonal AR time series are modelled and their coefficients are estimated, one can forecast the daily temperature values for the whole operation period, which in this study is 15 years (i.e., $t_{\text {end }}=15$ years). As shown in Figure 10, the forecasted temperatures (dotted line) have the same trend as that of historical data (solid line) and share similar seasonality and stochasticity.

To forecast the temperature data for a period of 15 years, the time horizon is divided into 5475 intervals with equal lengths of 1 day (i.e., $\Delta t_{K}^{\prime}=24$ hours). Yet, due to the randomness of the residual process, one may represent the aleatory uncertainties associated with forecasted temperatures by estimating the $5^{\text {th }}$ and $95^{\text {th }}$ quantiles of the forecasted values. For example, the forecasted temperatures for Hopen together with the double-sided $90 \%$ confidence bounds are shown in Figure 11 for a four-year period starting from 01.07.2016.

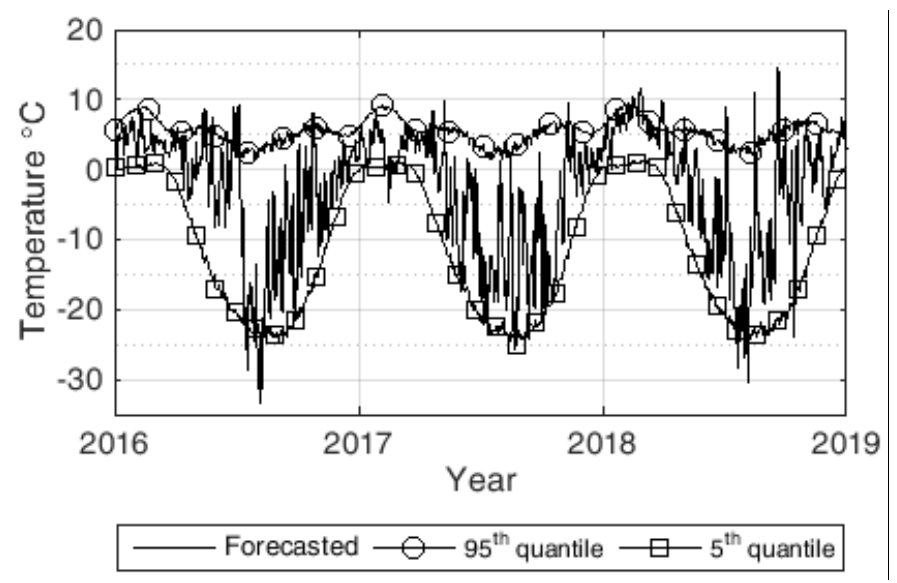

Figure 11. Forecast of minimum daily temperature and its double-sided 90\% confidence bound in Hopen for 4 years, starting from 01.07.2016

Having forecasted the temperatures for the operation time horizon of 15 years, one can obtain the values of the temperature-dependent factors $\delta_{L^{j}}$ for system components by comparing the forecasted daily temperatures against a set of pre-determined thresholds. This study assumes the range specified by Equation (24).

$$
\delta_{L_{K}, i}=\left\{\begin{array} { r l r } 
{ \delta _ { L ^ { 0 } , i } } & { \text { if } } & { { } ^ { \circ } \mathrm { C } \leq T _ { K } } \\
{ \delta _ { L ^ { 1 } , i } } & { \text { if } } & { - 5 ^ { \circ } \mathrm { C } \leq T _ { K } < 1 } \\
{ \delta _ { L ^ { 2 } , i } } & { \text { if } } & { - 1 0 ^ { \circ } \mathrm { C } \leq T _ { K } < - 5 ^ { \circ } \mathrm { C } ; } \\
{ \delta _ { L ^ { 3 } , i } } & { \text { if } } & { - 2 0 ^ { \circ } \mathrm { C } \leq T _ { K } < - 1 0 ^ { \circ } \mathrm { C } } \\
{ \delta _ { L ^ { 4 } , i } } & { \text { if } } & { T _ { K } < - 2 0 ^ { \circ } \mathrm { C } }
\end{array} \quad \left\{\begin{array}{l}
K=1,2, \ldots, 5475 \\
i=1,2, \ldots, 25
\end{array}\right.\right.
$$


where $\delta_{L^{j}, i} ; j=0, \ldots, 4$ is the weather-dependent factor for the hazard rate of component $i$ corresponding to WIL of $L^{j}$, and $T_{K}$ is the air temperature at platform location that has a constant value during the $K$ th day (i.e. at the time interval $\left[t_{K-1}^{\prime}, t_{K}^{\prime}\right)$ ). Values of temperature-dependent factors corresponding to each WIL are presented in Table 3. Note that the values of the weatherdependent factors and those of the thresholds to set the WILs are assumed to be elicited from experts.

Table 3. Weather-dependent parameters indicating the reduction in TTF and increase in TTR of the components

\begin{tabular}{|c|c|c|c|c|c|c|c|c|c|}
\hline \multirow{2}{*}{ Component ID } & \multicolumn{5}{|c|}{$\delta_{L^{j}, i}, j=0, \ldots, 5$} & \multicolumn{4}{|c|}{$\varepsilon_{L^{j}, i}, j=0, \ldots, 4$} \\
\hline & $\delta_{L^{0}, i}$ & $\delta_{L^{1}, i}$ & $\delta_{L^{2}, i}$ & $\delta_{L^{3}, i}$ & $\delta_{L^{4}, i}$ & $\varepsilon_{L^{0}, i}$ & $\varepsilon_{L^{1}, i}$ & $\varepsilon_{L^{2}, i}$ & $\varepsilon_{L^{3}, i}$ \\
\hline SEP1, SEP2, SEP3 & \multirow{3}{*}{1} & \multirow{3}{*}{0.90} & \multirow{3}{*}{0.70} & \multirow{3}{*}{0.55} & \multirow{3}{*}{0.45} & \multirow{9}{*}{1} & \multirow{9}{*}{2} & \multirow{9}{*}{3} & \multirow{9}{*}{4} \\
\hline GS4, GS5 & & & & & & & & & \\
\hline TEG & & & & & & & & & \\
\hline EP1, EP2, EP3 & 1 & 0.85 & 0.65 & 0.50 & 0.40 & & & & \\
\hline $\mathrm{H} 1, \mathrm{H} 2, \mathrm{H} 3, \mathrm{H} 4$ & 1 & 0.80 & 0.60 & 0.50 & 0.40 & & & & \\
\hline CS4, CS5 & 1 & 0.85 & 0.70 & 0.55 & 0.45 & & & & \\
\hline GEN1, GEN2, GEN3 & 1 & 0.85 & 0.65 & 0.5 & 0.40 & & & & \\
\hline GT3, GT4, GT5, GT6, GT7 & 1 & 0.85 & 0.60 & 0.45 & 0.35 & & & & \\
\hline TC3, TC4 & 1 & 0.90 & 0.70 & 0.50 & 0.40 & & & & \\
\hline
\end{tabular}

\subsubsection{Modelling the effects of low temperatures and winds on equipment repair rate}

This study focuses on the adverse effects of the combination of low temperatures and wind speeds only on crew performance that can result in extended repair times. The other waiting downtimes, such as administrative delays, are assumed independent of the weather conditions. High-speed winds increase the body heat loss, which results in a reduction in felt temperatures. This process is known as wind chill effect [55, 56]. Wind Chill Temperature (WCT) is defined as "the air temperature with no appreciable wind (i.e., still air) that would affect the same heat loss rate from exposed skin, as that due to the actual dry bulb temperature with wind" [56].

The term WCT is an equivalent temperature to account for wind speed contribution to felt temperatures. This study uses the WCT as a criterion to define the WILs for CM tasks. One of the most common wind chill models is developed in [55]. This model is also used by the US National Weather Service and the Canadian Weather Service, Environment Canada [55],

$$
\begin{aligned}
& W C T(K)=13.12+0.6215 \operatorname{TEMP}(K)-11.37 W \operatorname{IND}(K)^{0.16}+ \\
& 0.3965 \operatorname{TEMP}(K) W I N D(K)^{0.16} ;(K=1,2, \ldots, N)
\end{aligned}
$$

where $\operatorname{TEMP}(K)$ and $W I N D(K)$ are respectively air temperature in ${ }^{\circ} \mathrm{C}$ and wind speed in $\mathrm{km} / \mathrm{hr}$ at plant location.

\subsubsection{Forecasting long-term WCT}

From Equation (25), it arises that the long-term forecast of WCT requires both the temperature and wind speed forecasts. In the previous section, daily temperature forecasting by seasonal AR time-series model was discussed. In this study, a seasonal AR time-series model is adapted from $[53,57-59]$ to predict the long-term wind speed data. For this purpose, a set of historical wind speed data for the selected locations are taken from the online climate database of the Norwegian Metrological Institute available at http://eklima.met.no, to which the seasonal AR time series model is fitted. 
Similar to the approach adapted to model air temperature data, the seasonal AR time-series model can be applied to maximum daily wind speed data based on a conservative approach. Various deterministic components of the time series are modelled and eliminated through a stepby-step decomposition procedure. The seasonal AR time series to model and forecast the wind speed data is given by $[57,58]$ :

$$
W I N D^{\prime}(K)=S_{W}(K)+\sum_{p=1}^{\bar{P}} \bar{\alpha}_{p}\left[W I N D^{\prime}(K-p)-S_{W}(K-p)\right]+\sigma_{W}(K) \epsilon_{W}
$$

where $W I N D^{\prime}(K)$ is the Box-Cox transformed maximum daily wind speed $W I N D(K)$ (see the Appendix), $\bar{\alpha}_{p}, p=1, \ldots \bar{P}$ is the coefficient of $A R(\bar{P})$ process, $S_{W}(K)$ is the seasonality term, $\sigma_{W}(K)$ is the time-dependent standard deviation, and $\epsilon_{W}$ is the standard normal random process. The detailed approach to model and forecast wind speed temperatures as well as the estimated model parameters are given in the Appendix.

Having forecasted the wind speeds for the operation time horizon of 15 years, starting from 01.07.2016, WCTs can be estimated using Equation (25). The predicted WCTs over the time horizon together with the associated uncertainties represented by the double-sided $90 \%$ confidence bound are illustrated in Figure 12 for Hopen Arctic region for a four-year period from 01.07.2016.

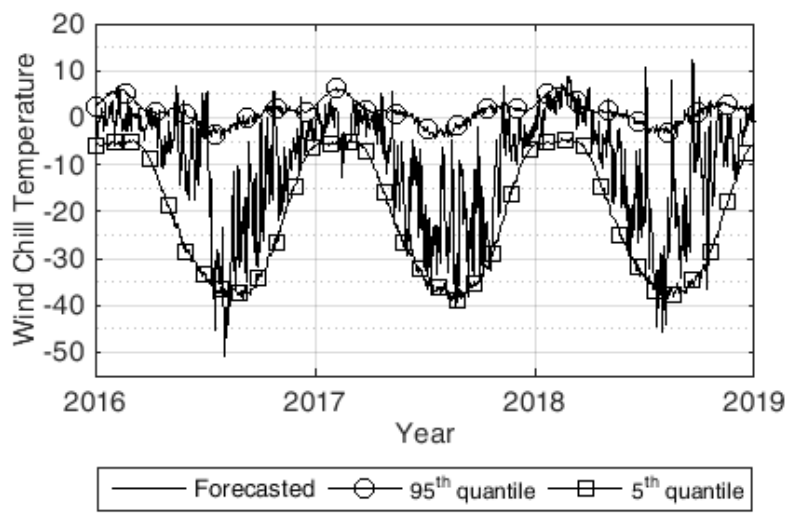

Figure 12. Forecast of daily WCT and its 95\% confidence bound in Hopen for 4 years, starting from 01.07.2016

The values of weather-dependent factors, $\varepsilon_{L^{j}, i}$ corresponding to WIL of $L^{j}$, can be obtained by comparing the forecasted WCT data against a set of pre-determined thresholds. This study assumes the range specified by Equation (27):

$$
\varepsilon_{L_{K}, i}=\left\{\begin{array}{rlr}
\varepsilon_{L^{0}, i} & \text { if } & -7 \leq W C T_{K} \\
\varepsilon_{L^{1}, i} & \text { if } & -15 \leq W C T_{K}<-7 \\
\varepsilon_{L^{2}, i} & \text { if } & -25 \leq W C T_{K}<-15 \\
\varepsilon_{L^{3}, i} & \text { if } & W C T_{K}<-25
\end{array} ; \quad\left\{\begin{array}{l}
K=1,2, \ldots, 5475 \\
i=1,2, \ldots, 25
\end{array}\right.\right.
$$

where $W C T_{K}$ is WCT at platform location at that has a constant value during the $K$ th day. Values of weather-dependent factors corresponding to each WIL are presented in Table 3.

\subsection{Results and discussion}

The instantaneous availability estimation of the oil processing train under the assumption of perfect and minimal repair is shown in Figure 13 for the locations of Hopen and Ekofisk, for the time horizon of 15 years, starting from 01.07.2016. The $1^{\text {st }}$ of July is chosen as the starting date 
of operation because in the Arctic offshore the plans are usually commissioned in summer, to prevent any possible delay or extended downtimes due to bad weather conditions. However, this assumption does not undermine the analyses. The corresponding plant mean availabilities over the time horizon are presented in Table 4. As can be seen, the plant availability in Hopen shows considerable reductions with respect to that of Ekofisk due to the adverse effects of harsh weather conditions, especially in winter times. For instance, under a perfect repair assumption, the plant mean availability reduces form 98.229\% in Ekofisk to 97.272\% in Hopen. The same conclusions can be drawn from the expected number of failures (Table 4). Considering a perfect repair assumption, on average the oil processing train operating in the base area has about 44 failures, whereas it has about 60 failures in the Barents Sea.
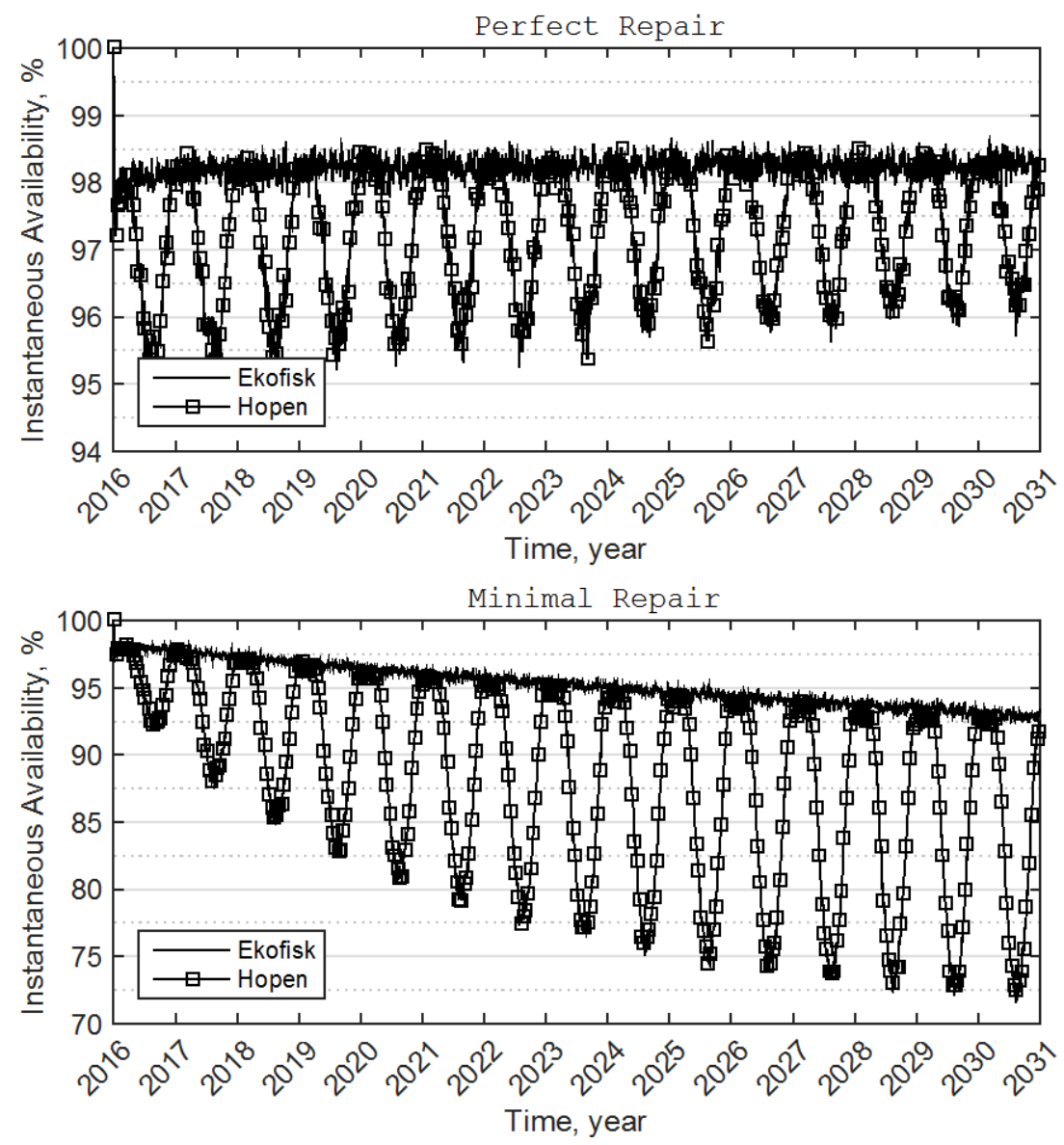

Figure 13. Instantaneous availability of the plant operating at different locations of the NCS for 15 years, starting from 01.07.2016

Table 4. Mean availabilities and expected number of failures for the oil processing train operating at different locations of the NCS for 15 years, starting from 01.07.2016

\begin{tabular}{|l|l|l|l|l|}
\hline \multirow{2}{*}{$\begin{array}{l}\text { Plant } \\
\text { location }\end{array}$} & \multicolumn{2}{|l|}{ Perfect repair } & \multicolumn{2}{l|}{ Minimal repair } \\
\cline { 2 - 5 } & $\begin{array}{l}\text { Mean } \\
\text { Availability, \% }\end{array}$ & $\begin{array}{l}\text { Expected No. } \\
\text { of Failure }\end{array}$ & $\begin{array}{l}\text { Mean } \\
\text { Availability, \% }\end{array}$ & $\begin{array}{l}\text { Expected No. } \\
\text { of Failure }\end{array}$ \\
\hline Hopen & $97.272 \pm 0.005$ & 59.89 & $88.407 \pm 0.009$ & 288.78 \\
\hline Ekofisk & $98.229 \pm 0.004$ & 43.85 & $95.289 \pm 0.005$ & 151.76 \\
\hline
\end{tabular}

The reductions in system availability over time are sharper in case of minimal repair. This is due to the preservation of all degradations due to aging of the components over time. Such degradations are accelerated in Arctic locations during winter times, with harsher weather conditions. For instance, the mean availability of the plant in Hopen reduces from $97.272 \%$ to 
88.407\% if minimal repair is assumed for the CM tasks. Similarly, since the components have preserved the degradations over time, the expected number of failures increases as well: more precisely, there is an increase from about 60 failures in 15 years for the perfect repair assumption to about 289 failures for the same period if the minimal repair is assumed.

\subsubsection{Sensitivity of plant availability to weather-dependent factors}

Various measures may be taken to improve plant reliability and availability performance. Winterization measures, such as insulation, are commonly performed in the Arctic O\&G platforms to protect both the equipment and crew against the harsh weather conditions. However, winterization practices are costly and require large efforts, whose provision is a challenging task in remote Arctic locations. Besides, although winterization measures may improve the reliability performance of the system components, they may contribute to an extended system downtime due to the time required for removing and re-installing the insulations if a component fails. Moreover, winterization measures act as active safety barriers, and, thus, their failure may result in high-risk scenarios. Analysing system availability can play an important role in providing adequate information for decision-makers to optimise winterization measures and to analyse to what extent the performance of the plant is affected in case of implementing certain winterization measures. The effects of harsh weather conditions on maintenance times can be also reduced by providing adequate clothing for maintenance crew, improving accessibility to the failed equipment by implementing anti-icing and de-icing measures, increasing the number of maintenance crew, to name but a few.

From the viewpoint of the failure and repair rate models developed in this study, the effects of modifications to the plant design (e.g. winterization, improving accessibility to the failed components) or to the comfort of maintenance crew and CM plans can contribute to the plant availability through the weather-dependent multiplicative factor $\delta_{L_{K}, i}$ and $\varepsilon_{L_{K}, i}$. In this regard, scenario-based analysing the sensitivity of the system availability performance to the potential changes in weather-dependent factors can provide essential information for decision-makers in the context of production optimisation.

To this aim, the plant mean availability is estimated for a number of scenarios, corresponding to each weather-dependent multiplicative factor with the values of $\delta_{L_{K}, i} \neq 1$ and $\varepsilon_{L_{K}, i} \neq 1$ varied by certain percentages $X$ and $Y$, respectively. More specifically, for each scenario, $\delta_{L_{K}, i}$ and $\varepsilon_{L_{K}, i}$ are substituted by their modified values $\delta_{L_{K}, i}(1+X)$ and $\varepsilon_{L_{K}, i}(1-Y)$ to represent the improvement in the reliability and maintainability performance of the components through increasing the values of $\delta_{L_{K}, i}$ and $\varepsilon_{L_{K}, i}$ by a factor of $X$ and $Y$ (increase and decrease, respectively). Note that $\delta_{L_{K}, i}=1$ refers to the days during which the weather conditions are considered normal and, thus, equipment failure does not depend upon winterization measures. Additionally, it is assumed that the improvements in the comfort of maintenance crew do not reduce active repair time less than under normal climate conditions. This assumption implies that the potential changes in $\varepsilon_{L_{K}, i}$ are not applied for the days where $\varepsilon_{L_{K}, i}=1$. However, one should also notice that applying design modifications and winterization measures could affect both the failure and repair times, simultaneously. For example, although installing insulations can result in a reduced failure rate, it causes extended downtimes in CM tasks, as the insulations must be removed from the failed component and placed back after repair is performed. The sensitivity of the plant availability to such dependencies is not analysed in this study. 
By taking $X=\{-0.1,0.05,0,0.05,0.1,0.15\}$ and $Y=\{-0.1,0.05,0,0.05,0.1,0.15\}$, a total number of 36 scenarios for plant availability assessment are investigated. Note that positive values of $X$ and $Y$ indicate an improvement in component reliability performance and a reduction in maintenance times, respectively, while negative ones refer to an increase in hazard rates and component active repair times. The baseline case is $X=Y=0$, indicating that no changes are applied to the plant design. The plant mean availability for a production period of 15 years under the assumption of minimal repair, is plotted for the defined sets of $X$ and $Y$ in Figure 14-a. As can be seen, an increase in $\delta_{L_{K}, i}$ raises plant availability by reducing the hazard rate of the components. Similarly, system availability can be improved by applying procedures or modifications that can reduce the active repair times. The same trend is present in Figure 14-b, where the expected number of failures are plotted versus the changes in the weather-dependent factors, where the number of system downtimes is considerably increased in comparison to a reduction in $\delta_{L_{K}, i}$. However, as can be seen in Figures 14-a and 14-b, the changes in $\varepsilon_{L_{K}, i}$ do not considerably affect the expected number of failures and plant mean availability. For instance, while no design modifications are applied to improve the hazard rates (i.e., $X=0$ ), a $10 \%$ reduction in the values of $\varepsilon_{L_{K}, i}$ results in a reduction in expected number of failures by less than one failure. However, a $10 \%$ increase in the values of $\delta_{L_{K}, i}$ leads to a decrease in the expected number of failures from 289.27 to 261.56.
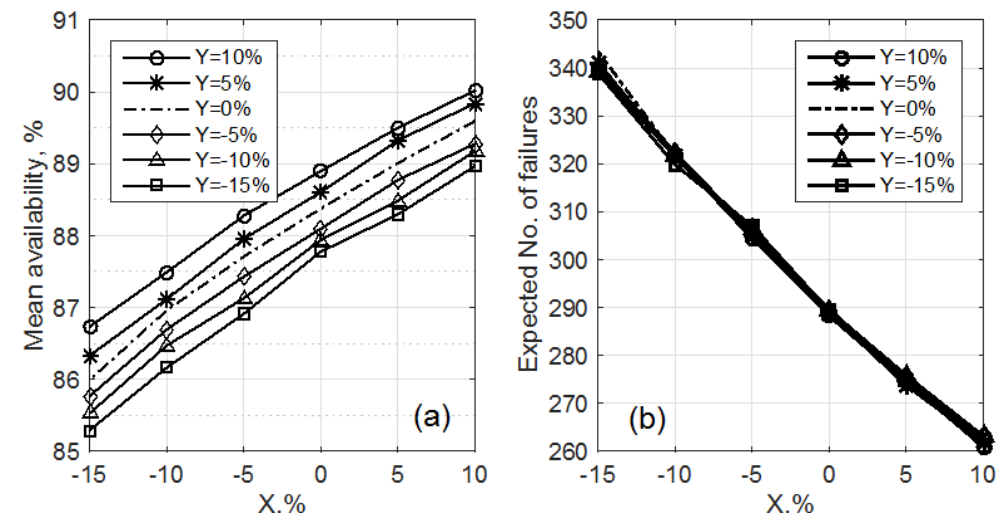

Figure 14. Plant mean availability (a) and expected number of failures (b) as a function of changes in weatherdependent factors

\subsubsection{Plant availability under scheduled PM}

PM actions are performed to retain an item in a specified condition by providing systematic inspection, detection, and prevention of incipient failures [60]. The aim of performing PM tasks can be reducing the number of failures, improving system safety, increasing plant production rate, and reducing unplanned system downtimes [61-63]. Among different approaches to PM tasks, this study considers a calendar-based scheduled PM, whose impact on system performance is assessed in terms of plant availability and expected number of failures.

A number of approaches have been propounded in the literature to cope with the issue of setting a PM policy $[62,64]$. In this study, the PM is of an overhaul type, taking place every $\tau_{P M}$ years, for a period of 3 weeks considering normal weather conditions. The underlying assumption is that the PM renews all the components (i.e., the starting age of the components is set to zero after being subjected to PM). This type of PM affects plant availability in two ways: i) it reduces plant availability by imposing shutdowns every $\tau_{P M}$ years for a period of 3 weeks, and ii) it 
improves plant availability by removing all the previous degradations from components' history, and thus reducing system hazard rates.

Therefore, determining the optimal maintenance interval (i.e., the time spans between two successive maintenance actions) plays a key role in maximising the overall profitability of the plant taking account of, namely, PM costs, CM costs, plant production, and safety issues [61-63]. This study includes only the plant availability and expected number of failures as the criteria for optimising $\tau_{P M}$. To this aim, the plant availability is analysed for $\tau_{P M}=\{1, \ldots, 6\}$ years. The mean availabilities and expected number of failures are shown in Figures 15-a and 15-b, respectively. As illustrated in Figures 15-a, with a PM interval of $\tau_{P M}=2,3$, and 4 years, the plant availabilities are 93.42\%, 93.07\%, and 93.02\%, while as shown in Figure 15-b the expected number of failures are 111.18, 132.55, and 147.35. By comparing such results, $\tau_{P M}=2$ years is selected as the optimum PM interval. Figure 16 compares the plant instantaneous availability for two cases of operating without any PM and when the plant is completely shut down every 2 years for an overhaul. During the first 2 years, the plant availability is identical in both cases. However, when the first PM is implemented at the end of the second year, the plant availability is considerably improved compared to the operation where no PM policy is in place. Such differences in availabilities become larger as components age over time. For instance, the instantaneous availability of the plant during the winter of the $15^{\text {th }}$ year of the plant is about $71.48 \%$, which will be increased to $92.90 \%$ in case of a PM with a 2-year interval.
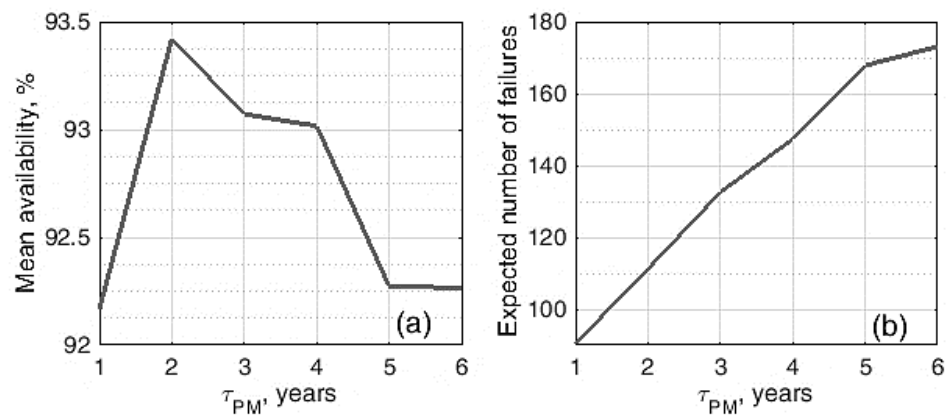

Figure 15. Plant mean availability (a) and expected number of failures (b) corresponding to different PM intervals

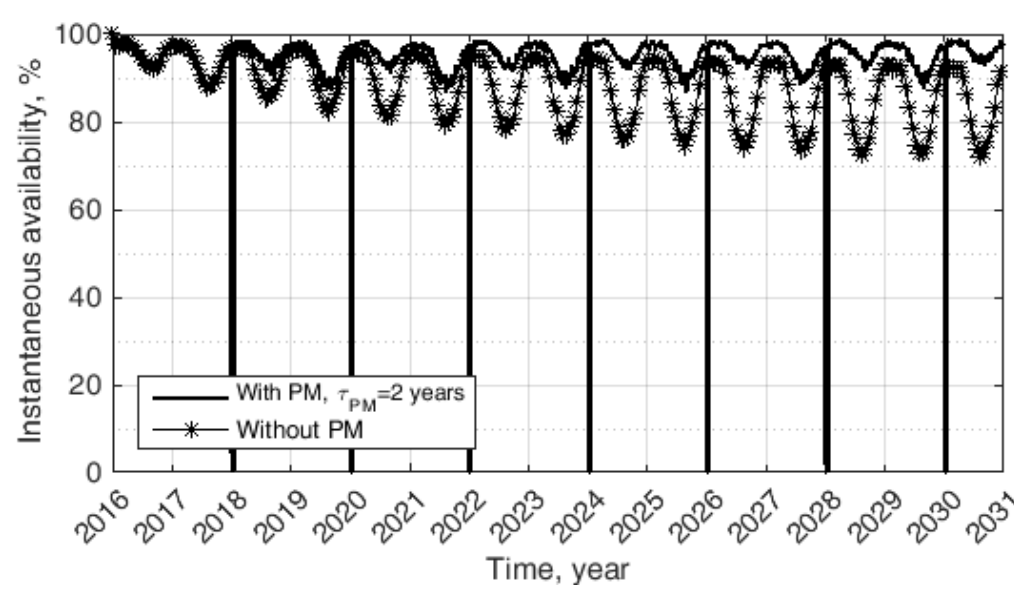

Figure 16. Plant instantaneous availability with and without PM

\subsubsection{Propagation of uncertainties associated with weather conditions}

Long-term forecasting of weather conditions is affected by epistemic uncertainty, which is due to the incomplete knowledge on the model and parameters $[65,66]$, and by aleatory uncertainty associated with weather conditions originating from inherent variability of the weather behaviour. 
In this study, the inherent randomness of the weather conditions is modelled by sampling two realisations from standard normal distribution for the final residuals of the seasonal AR timeseries model to forecast long-term temperature and wind speeds (i.e., the first stochastic process shown in Figure 6). This process is repeated in each simulation run until sufficiently large amount of lifetime scenarios are generated. Figure 17 shows the instantaneous availability of the oil processing train for a 15-year production period starting from 01.07.2016 under minimal repair assumption using the aforementioned approach. The corresponding mean availability and expected number of failures are $88.407 \pm 0.009 \%$ and 288.78 , respectively.
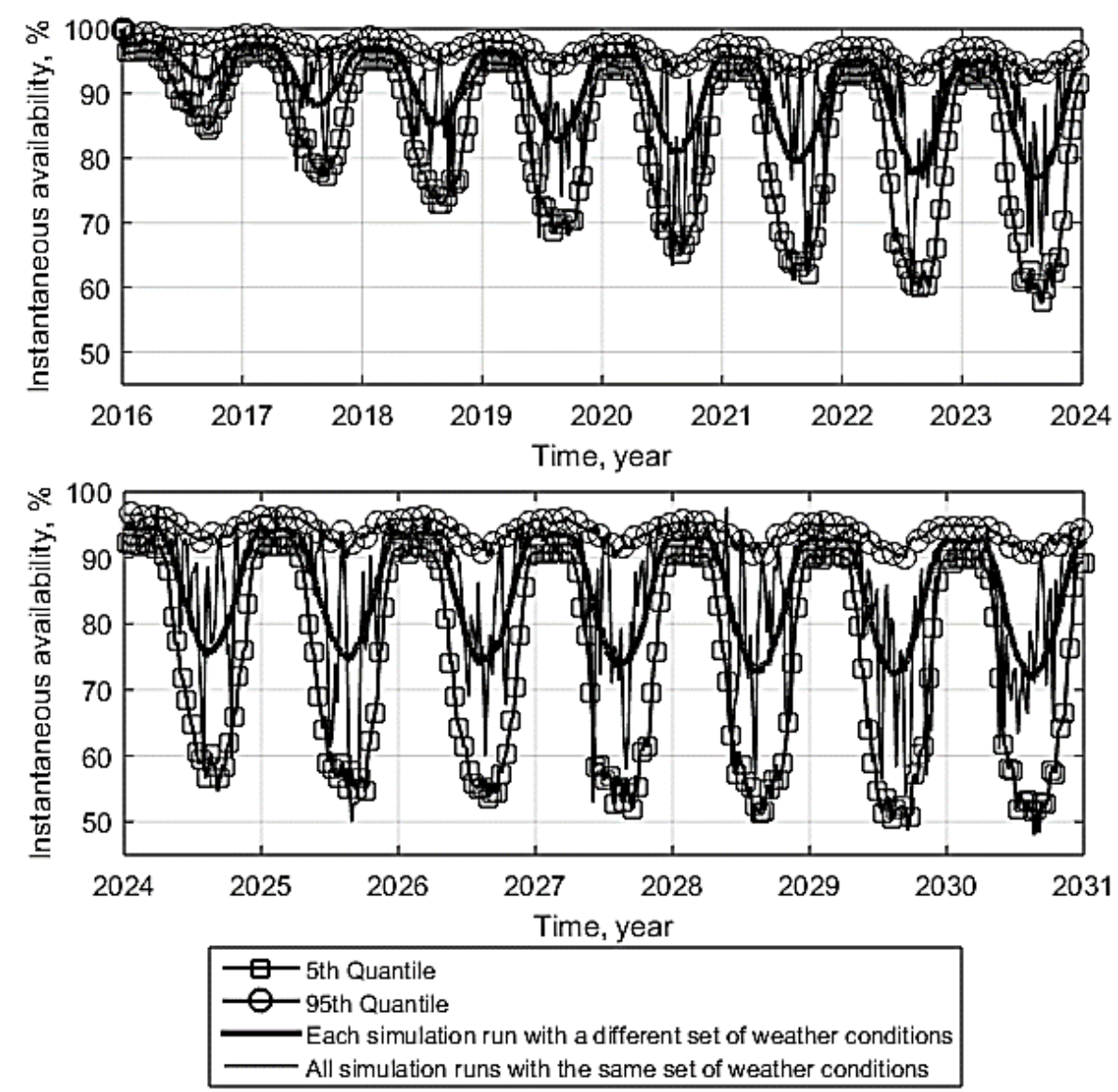

Figure 17. Instantaneous availability of the plant for a production period of 15 years starting from 01.07.2016, estimated using variable and fixed sets of weather conditions

Alternatively, as for the first step, one may generate a set of temperature and wind speed values, based on which the weather-dependent multiplicative factors are determined. Such factors are, then, used for all MC simulation runs (Figure 17). Using this approach, the system availability can vary considerably depending on the set of forecasted weather conditions with sharp changes over the production time horizon. The 95\% confidence bounds of the estimated instantaneous and mean availabilities can, then, be obtained by repeating this approach for a sufficiently large number of times. The $5^{\text {th }}$ and $95^{\text {th }}$ quantiles of the estimated instantaneous availabilities are shown in Figure 17. It can be seen that the differences between the $5^{\text {th }}$ and $95^{\text {th }}$ quantiles are much wider during the winter season: this is because the temperature and WTC experience large variations during winter season compared to those in other seasons. Such large variations are also evident in Figure 10.

By comparing the two mentioned approaches, one can conclude that the differences in instantaneous availabilities during summer times are comparatively close compared to those 
estimated for the winter periods. Such large differences in instantaneous availabilities lead to considerable different estimations of plant mean availabilities and expected number of failures. The empirical PDF of estimated mean availabilities and expected number of failures are depicted in Figure 18. The 95\% confidence bounds of plant mean availability and expected number of failures are [87.67\%, 89.11\%] and [277.04, 301.94], respectively, while using the former approach, the plant mean availability is $88.407 \%$ and it experiences 288.78 failures on average.

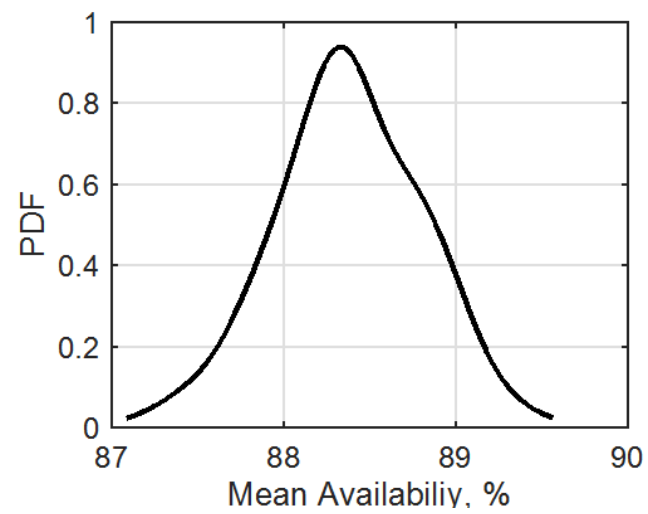

Figure 18. The empirical PDF of plant mean availability in the presence of uncertainties associated with weather condition forecasts

\section{Conclusions}

This study has concerned the problem of assessing system availability under dynamic operating conditions due to weather changes. To this aim, weather-dependent failure and repair rates have been modelled by analogy with step-stress ALT models. The models have been built assuming that the variable operating conditions do not induce a change in the failure mechanisms. According to the developed reliability and maintainability models, the functional form of the failure and repair rates follows the current WIL and the effects of previous exposures contribute to the models through the use of an equivalent age. For this purpose, a cumulative exposure model is applied.

Given the complexities of dynamic operating conditions and their effects on the maintenance and operation of multi-component systems, obtaining an analytical expression for system availability is not feasible. Hence, a direct MC approach has been used to capture the impacts of dynamic and severe weather conditions. Assumptions of perfect and minimal repairs have been considered.

The proposed model has been illustrated by analysing the availability of a typical oil processing train in offshore O\&G production plants. To apply dynamic weather conditions, Hopen Island, a location in the Barents Sea has been chosen where the environmental conditions change through the year. The stochasticity of the air temperatures and wind speeds have been effectively modelled using seasonal AR time series. Defining a threshold for the normal climate conditions illustrated that although the overall weather conditions are harsher in the Barents Sea, in summer seasons the weather conditions can be considered normal. This approach results in lower uncertainties compared to the cases, where the weather conditions are assumed constant at a harsher level throughout the year. However, the stochastic behaviour of the weather conditions imposes some uncertainties to the weather forecasts, and thus to the resulting system availability under dynamic weather conditions. Such uncertainties are effectively represented by estimating the $5^{\text {th }}$ and $95^{\text {th }}$ quantiles of estimated instantaneous availabilities. 
Over long time horizons, e.g., 15 years, system components can age considerably resulting in reduced availability. To cope with such reductions, PM was considered to find an optimum interval to perform the overhauls. System mean availability and expected number of failures were used as criteria to optimize. In the application, it turned out that a PM on a 2-year basis leads to considerable improvement in plant availability and reduction in the number of unplanned downtimes.

Defining the thresholds of WILs and estimating the degree of changes in TTFs and TTRs corresponding to such WILs remain issues that require further research. In this study, it was assumed that operational data are available in some locations. Such data were modified in accordance to the changes in weather conditions. Alternatively, some other methods relying on PHMs, ALMs and expert opinions can be also used to estimate the values of weather-dependent factors, all of which can be used in failure and repair models proposed in this study.

Furthermore, the developed model can be used during the design phase if the life data in the operation location are scarce. This is of special interest in the context of O\&G operations in the Arctic, where the weather conditions are harsh. To highlight the application of the proposed model in decision-making processes during the design of the O\&G platforms for Arctic regions, the concept of winterization and its impacts on plant availability were discussed through analysing the system availability sensitivity to the weather-dependent factors. Based on the sensitivity analysis results, the plant availability is shown to be more sensitive to the effects of weather conditions on equipment hazard rates than on maintenance duration.

\section{$5 \quad$ Appendix - forecasting long-term air temperatures and wind speeds}

Seasonal auto-regressive AR time series is a common model to forecast the long-term daily air temperatures and wind speeds, while taking into account their seasonality and stochastic behaviours. A step-by-step approach can be used to model different deterministic and stochastic terms of the time series and estimate the model parameters values. The reader is referred to [5054 , 58, 59] for further details on the model development, its underlying assumptions and applications.

The main difference in modelling the air temperatures and wind speeds is that the wind speeds must be transformed prior to applying the time series model. A Box-Cox transformation is usually applied to the raw wind speed data, given by $[53,57,58]$ :

$$
W I N D^{\prime}(t)= \begin{cases}\frac{W I N D^{\omega}(t)-1}{\omega} & \text { for } \omega \neq 0 \\ \ln \omega & \text { for } \omega=0\end{cases}
$$

The values of the transformation parameters, $\omega$, are estimated by minimising the log-likelihood function of Equation (A-1) (Table A-1). The time-series model is, then, fitted to the transformed wind speed data.

Table A-1. Parameters of the Box-Cox transformation for the considered locations in the NCS

\begin{tabular}{|l|l|}
\hline Region & $\omega$ \\
\hline Hopen & 0.627 \\
\hline Ekofisk & 0.413 \\
\hline
\end{tabular}

Let us denote the minimum daily air temperatures and transformed maximum daily wind speeds by TEMP and $W I N D^{\prime}$ respectively. Further, let us denote the weather element by $W E$, such that $W E \in\left\{T E M P, W I N D^{\prime}\right\}$. The seasonal AR time series model for $W E$ is, then, given by, 


$$
W E(t)=\overline{W E}(t)+\psi(t)
$$

where $\overline{W E}(t)$ and $\psi(t)$ are the mean and residual processes, respectively. The mean term is given by $[52,57,58]$,

$$
\overline{W E}(t)=S(t)+\sum_{p=1}^{P} \alpha_{p}[W E(t-p)-S(t-p)]
$$

with $\alpha_{p}, p=1, \ldots, P$ being the parameters of the AR process of order $P$, indicated by $A R(P)$, and $S(t)$ being the deterministic trend function, which consists of linear and cyclic terms given by $[52,57,58]$,

$$
S(t)= \begin{cases}l_{0}+l_{1} t+\sum_{v=1}^{V} a_{0}^{v} \cos \left(\frac{2 \pi}{365}\left(t-a_{1}^{v}\right)\right) & \text { for } \quad W E=\text { TEMP } \\ l_{0}+l_{1} t+\sum_{v=1}^{V}\left[a_{0}^{v} \cos \left(\frac{2 \pi v}{365} t\right)+a_{1}^{v} \sin \left(\frac{2 \pi v}{365} t\right)\right] & \text { for } \quad W E=W^{\prime} D^{\prime}\end{cases}
$$

Furthermore, the residual process $\psi(t)$ is expressed by [52, 57, 58],

$$
\psi(t)=\sigma(t) \epsilon
$$

where $\epsilon$ is a zero-mean and temporally independent standard normal random process and $\sigma(t)$ is a seasonally time-dependent standard deviation function, describing the remaining heteroskedasticity in air temperature and transformed wind speed residuals. The seasonal variance, $\sigma^{2}(t)$ can be obtained by fitting a truncated Fourier series to the squared of the residuals, i.e., $\psi^{2}(t)[52,57,58]$ :

$$
\sigma^{2}(t)=b_{0}+\sum_{v=1}^{V^{\prime}}\left[b_{0}^{v} \cos \left(\frac{2 \pi v}{365} t\right)+b_{1}^{v} \sin \left(\frac{2 \pi v}{365} t\right)\right]
$$

The first step to use the aforementioned model is to estimate and remove the linear and cyclic trends of the data. The data are fitted to the function given by Equation (A-4) with $V=2$ and $V=4$, for $W E=T E M P$ and $W E=W I N D^{\prime}$, respectively. Such orders are chosen as they provide the simplest terms able to remove the seasonality from the data.

Once the seasonality terms are removed, the residuals are checked for autocorrelation using the Ljung-Box test at a significance level of 5\%. The possible autocorrelation is removed from the data by introducing the AR structure of order $P, A R(P)$. The order $P$ is determined by trying different values of $P$ starting from 1 and selecting the first for which the autocorrelation test for the residuals is rejected at a significance level of $5 \%$ (i.e., the residuals become noncorrelated). To model the seasonal variance of the residuals, $\sigma^{2}(t)$, the squared of residual terms, $\psi(t)$, is fitted to a truncated Fourier series of order 3 , as by using such an order the seasonality of the $\sigma^{2}(t)$ is effectively removed. The final model residuals, $\epsilon$, then, can be obtained by dividing the residuals of $A R(P)$ by the square root of $\sigma^{2}(t)$. The coefficients of $\sigma^{2}(t)$ together with the mean and standard deviation of the final residuals are presented in Tables A-2, and A-3 for air temperatures and wind speed data, respectively. The developed time-series model is validated using both the in-sample and out-of-sample data, based on which the generated temperature data using the model lie within the $95 \%$ confidence bounds.

Once the model parameters are estimated, one can forecast the daily temperature and wind speed values for the operation time horizon by estimating different terms of the developed seasonal AR time series models.

The coefficients of the developed seasonal AR time series models are given in Tables A2 and A-3, for air temperature and wind speed, respectively. The coefficients of the AR processes, which are not statistically significant at $5 \%$ are excluded from the analysis. 
Table A-2. Coefficients of the different terms of temperature seasonal AR time series model

\begin{tabular}{|c|c|c|c|c|c|c|c|}
\hline \multirow[t]{2}{*}{ Region } & \multirow[t]{2}{*}{ Linear trend } & \multirow[t]{2}{*}{ Cyclic term } & \multirow[t]{2}{*}{$A R(P)$ term } & \multirow{2}{*}{$\begin{array}{c}\text { Seasonal } \\
\text { variance } \\
\text { term }\end{array}$} & \multicolumn{3}{|c|}{ Final residuals } \\
\hline & & & & & Mean & Std. & Skewness \\
\hline Hopen & $\begin{array}{ll}l_{0} & -9.0721 \\
l_{1} & 0.0005513\end{array}$ & \begin{tabular}{|ll}
$a_{0}^{1}$ & -8.4996 \\
$a_{1}^{1}$ & -327.1807 \\
$a_{0}^{2}$ & 0.8516 \\
$a_{1}^{2}$ & 22.5809
\end{tabular} & \begin{tabular}{|ll}
$\alpha_{1}$ & 0.9662 \\
$\alpha_{2}$ & -0.2558 \\
$\alpha_{3}$ & 0.1011 \\
$\alpha_{6}$ & 0.0327 \\
$\alpha_{8}$ & 0.0342
\end{tabular} & \begin{tabular}{|ll}
$b_{0}$ & 9.220 \\
$b_{0}^{1}$ & 8.6250 \\
$b_{1}^{1}$ & 5.2140 \\
$b_{0}^{2}$ & -0.2275 \\
$b_{1}^{2}$ & 1.5310 \\
$b_{0}^{3}$ & -0.9916 \\
$b_{1}^{3}$ & -1.5170
\end{tabular} & 0.0048 & 1.0262 & 0.2257 \\
\hline Ekofisk & $\begin{array}{ll}l_{0} & 7.7212 \\
l_{1} & 0.0002120\end{array}$ & \begin{tabular}{|ll}
$a_{0}^{1}$ & 5.1116 \\
$a_{1}^{1}$ & -139.1165 \\
$a_{0}^{2}$ & 0.8187 \\
$a_{1}^{2}$ & 31.9496
\end{tabular} & $\begin{array}{ll}\alpha_{1} & 0.7721 \\
\alpha_{2} & -0.0569 \\
\alpha_{3} & 0.0414 \\
\alpha_{8} & 0.0393 \\
\alpha_{9} & -0.0440 \\
\alpha_{10} & -0.0434\end{array}$ & \begin{tabular}{|ll}
$b_{0}$ & 1.342 \\
$b_{0}^{1}$ & 0.6253 \\
$b_{1}^{1}$ & 0.1435 \\
$b_{0}^{2}$ & 0.0961 \\
$b_{1}^{2}$ & 0.1316 \\
$b_{0}^{3}$ & -0.0517 \\
$b_{1}^{3}$ & 0.0770 \\
\end{tabular} & 0.0004 & 1.0006 & -0.1506 \\
\hline
\end{tabular}

Table A-3. Coefficients of the different terms of wind speed seasonal AR time series model

\begin{tabular}{|c|c|c|c|c|c|c|c|}
\hline \multirow[t]{2}{*}{ Region } & \multirow[t]{2}{*}{ Linear trend } & \multirow[t]{2}{*}{ Cyclic term } & \multirow[t]{2}{*}{$A R(P)$ term } & \multirow{2}{*}{$\begin{array}{c}\text { Seasonal } \\
\text { variance } \\
\text { term }\end{array}$} & \multicolumn{3}{|c|}{ Final residuals } \\
\hline & & & & & Mean & Std. & Skewness \\
\hline Hopen & \begin{tabular}{|ll}
$\bar{l}_{0}$ & 10.071 \\
$\bar{l}_{1}$ & 0.0001007
\end{tabular} & $\begin{array}{ll}\bar{a}_{0}^{1} & 1.245 \\
\bar{a}_{1}^{1} & -0.2233 \\
\bar{a}_{0}^{2} & -0.1993 \\
\bar{a}_{1}^{2} & 0.1886 \\
\bar{a}_{0}^{3} & -0.2081 \\
\bar{a}_{1}^{3} & -0.03532 \\
\bar{a}_{0}^{4} & 0.2506 \\
\bar{a}_{1}^{4} & 0.02481\end{array}$ & \begin{tabular}{|ll}
$\bar{\alpha}_{1}$ & 0.3190 \\
$\bar{\alpha}_{4}$ & 0.0307
\end{tabular} & \begin{tabular}{|ll}
$\bar{b}_{0}$ & 8.74 \\
$\bar{b}_{0}^{1}$ & 1.712 \\
$\bar{b}_{1}^{1}$ & 0.8134 \\
$\bar{b}_{0}^{2}$ & -0.0500 \\
$\bar{b}_{1}^{2}$ & 0.2107 \\
$\bar{b}_{0}^{3}$ & 0.1376 \\
$\bar{b}_{1}^{3}$ & -0.1672
\end{tabular} & -0.0002 & 1.0000 & -0.0936 \\
\hline Ekofisk & $\mid \begin{array}{ll}\bar{l}_{0} & 8.661 \\
\bar{l}_{1} & -6.244 \mathrm{E}-05\end{array}$ & $\begin{array}{ll}\bar{a}_{0}^{1} & 0.937 \\
\bar{a}_{1}^{1} & -0.1646 \\
\bar{a}_{0}^{2} & -0.0170 \\
\bar{a}_{1}^{2} & 0.1673 \\
\bar{a}_{0}^{3} & 0.0957 \\
\bar{a}_{1}^{3} & 0.0977 \\
\bar{a}_{0}^{4} & 0.0072 \\
\bar{a}_{1}^{4} & -0.0526\end{array}$ & $\begin{array}{ll}\bar{\alpha}_{1} & 0.4917 \\
\bar{\alpha}_{2} & -0.0396 \\
\bar{\alpha}_{3} & -0.0480\end{array}$ & \begin{tabular}{|ll}
$\bar{b}_{0}$ & 1.886 \\
$\bar{b}_{0}^{1}$ & 0.3287 \\
$\bar{b}_{1}^{1}$ & 0.1633 \\
$\bar{b}_{0}^{2}$ & -0.0462 \\
$\bar{b}_{1}^{2}$ & -0.0072 \\
$\bar{b}_{0}^{3}$ & -0.026 \\
$\bar{b}_{1}^{3}$ & -0.0786
\end{tabular} & -0.0008 & 1.0002 & -0.1751 \\
\hline
\end{tabular}

\section{References}

[1] Gudmestad OT, Karunakaran D. Challenges Faced by the Marine Contractors Working in Western and Southern Barents Sea. OTC Arctic Technology Conference. 3-5 December, Houston, Texas, USA2012.

[2] Løset S, Shkhinek K, Gudmestad OT, Strass P, Michalenko E, Frederking R, et al. Comparison of the physical environment of some Arctic seas. Cold Regions Science and Technology. 1999;29:201-14.

[3] Homlong E, Kayrbekova D, Panesar SS, Markeset T. Assessing Maintenance Time, Cost and Uncertainty for Offshore Production Facilities in Arctic Environment. In: Frick J, Laugen BT, editors. Advances in Production Management Systems - Value Networks: Innovation, Technologies, and Management: Springer; 2012.

[4] Naseri M, Barabady J. Offshore drilling activities in Barents Sea: Challenges and considerations. Proceedings of the 22nd International Conference on Port and Ocean Engineering under Arctic Conditions (POAC). June 9-13, Espoo, Finland2013. 
[5] Jardine A, Anderson P, Mann D. Application of the Weibull proportional hazards model to aircraft and marine engine failure data. Quality and reliability engineering international. 1987;3:77-82.

[6] Doyen L, Gaudoin 0. Classes of imperfect repair models based on reduction of failure intensity or virtual age. Reliability Engineering \& System Safety. 2004;84:45-56.

[7] Kumar D, Klefsjö B. Proportional hazards model: a review. Reliability Engineering \& System Safety. 1994;44:177-88.

[8] Dale CJ. Application of the proportional hazards model in the reliability field. Reliability Engineering. 1985;10:1-14.

[9] Ansell JI, Philipps MJ. Practical aspects of modelling of repairable systems data using proportional hazards models. Reliability Engineering \& System Safety. 1997;58:165-71.

[10] Martorell S, Sanchez A, Serradell V. Age-dependent reliability model considering effects of maintenance and working conditions. Reliability Engineering \& System Safety. 1999;64:19-31.

[11] Vesely WE, Wolford AJ. Risk evaluations of aging phenomena: The linear aging reliability model and its extensions. Nuclear Engineering and Design. 1988;108:179-85.

[12] Martón I, Sánchez AI, Martorell S. Ageing PSA incorporating effectiveness of maintenance and testing. Reliability Engineering \& System Safety. 2015;139:131-40.

[13] Artiba A, Riane F, Ghodrati B, Kumar U. Reliability and operating environment-based spare parts estimation approach: a case study in Kiruna Mine, Sweden. Journal of Quality in Maintenance Engineering. 2005;11:169-84.

[14] Gao X, Barabady J, Markeset T. An approach for prediction of petroleum production facility performance considering Arctic influence factors. Reliability Engineering \& System Safety. 2010;95:837-46.

[15] Tian L, Zucker D, Wei LJ. On the Cox Model With Time-Varying Regression Coefficients. Journal of the American Statistical Association. 2005;100:172-83.

[16] Peng L, Huang Y. Survival Analysis with Temporal Covariate Effects. Biometrika. 2007;49:719-33.

[17] Rocchetta R, Li YF, Zio E. Risk assessment and risk-cost optimization of distributed power generation systems considering extreme weather conditions. Reliability Engineering \& System Safety. 2015;136:47-61.

[18] Alvehag K, Soder L. A stochastic weather dependent reliability model for distribution systems. Proceedings of the 10th International Conference on Probabilistic Methods Applied to Power Systems (PMAPS08). May 25-29, Rincón, Puerto Rico: IEEE; 2008. p. 1-8. [19] Alvehag K, Soder L. A reliability model for distribution systems incorporating seasonal variations in severe weather. IEEE Transactions on Power Delivery. 2011;26:910-9.

[20] Barabadi A, Barabady J, Markeset T. Maintainability analysis considering timedependent and time-independent covariates. Reliability Engineering \& System Safety. 2011;96:210-7.

[21] Barabadi A, Barabady J, Markeset T. Application of reliability models with covariates in spare part prediction and optimization - A case study. Reliability Engineering \& System Safety. 2014;123:1-7.

[22] Kayrbekova D, Barabadi A, Markeset T. Maintenance cost evaluation of a system to be used in Arctic conditions: a case study. Journal of Quality in Maintenance Engineering. 2011;17:320-36.

[23] Barabadi A, Gudmestad OT, Barabady J. RAMS data collection under Arctic conditions. Reliability Engineering \& System Safety. 2015;135:92-9.

[24] Baraldi P, Compare M, Despujols A, Zio E. Modelling the effects of maintenance on the degradation of a water-feeding turbo-pump of a nuclear power plant. Journal of Risk and Reliability. 2011;225:169-83. 
[25] Baraldi P, Zio E, Compare M, Rossetti G, Despujols A. A novel approach to model the degradation of components in electrical production plants. In: Bris R, Soares CG, Martorell S, editors. Proceedings of 18th European Safety and Reliability Conference. Prague CRC Press; 2009.

[26] Naseri M, Barabady J. Expert-Based Reliability Modelling and Analysis of Arctic Oil and Gas Production Plants: Accounting for the Effects of Harsh Weather Conditions. Submitted to a journal for publication. 2015.

[27] Department of Defense. Military Handbook MIL-HDBK-217F - Reliability Predition of Electronic Equipment. Washington D.C.: Department of Defense; 1991.

[28] Kijima M. Some results for repairable systems with general repair. Journal of Applied probability. 1989;26:89-102.

[29] Baraldi P, Balestrero A, Compare M, Benetrix L, Despujols A, Zio E. A modeling framework for maintenance optimization of electrical components based on fuzzy logic and effective age. Quality and Reliability Engineering International. 2013;29:385-405.

[30] XiaoFei L, Min L. Hazard rate function in dynamic environment. Reliability Engineering \& System Safety. 2014;130:50-60.

[31] Naseri M, Barabady J. An expert-based approach to production performance analysis of oil and gas facilities considering time-independent Arctic operating conditions. International Journal of System Assurance Engineering and Management. 2016:1-15.

[32] Murthy DNP, Xie M, Jiang R. Weibull Models. New Jersey: John Wiley \& Sons; 2004.

[33] Rausand M, Høyland A. System reliability theory: models, statistical methods, and applications: John Wiley \& Sons; 2004.

[34] Mannan S. Lees' Process Safety Essentials: Hazard Identification, Assessment and Control. Oxford: Butterworth-Heinemann; 2014.

[35] Zio E. The Monte Carlo Simulation Method for System Reliability and Risk Analysis. London: Springer; 2013.

[36] Elsayed EA. Reliability Engineering. 2nd ed. Hoboken: John Wiely \& Sons; 2012.

[37] Bagdonavicius V, Nikulin M. Accelerated life models: modeling and statistical analysis: CRC press; 2001.

[38] Zio E. An introduction to the basics of reliability and risk analysis: World scientific; 2007.

[39] Cox DR. Regression Models and Life-Tables. Journal of the Royal Statistical Society. 1972;34:187-220.

[40] Dubi A. Monte Carlo Applications in Systems Engineering. Chichester:: Wiley; 2000.

[41] Dubi A. Analytic approach \& Monte Carlo methods for realistic system analysis. Mathematics and Computers in Simulation. 1998;47:243-69.

[42] Siu N. Risk assessment for dynamic systems: An overview. Reliability Engineering \& System Safety. 1994;43:43-73.

[43] OREDA Participants. Offshore Reliability Data Handbook 5th ed. Trondhim: OREDA Participants; 2009.

[44] Obanijesu EO, Akindeju MK, Vishnu P, Tade MO. Modelling the Natural Gas Pipeline Internal Corrosion Rate Resulting from Hydrate Formation. In: Pistikopoulos EN, Georgiadis MC, Kokossis AC, editors. Computer Aided Chemical Engineering: Elsevier; 2011. p. 1160-4.

[45] Dutta PK. Behaviour of materials at cold regions temperatures - Part 1: Program rationale and test plan. New Hampshire: US Army Engineer Research and Development Centre; 1988.

[46] Rudin A, Choi P. Chapter 4 - Mechanical Properties of Polymer Solids and Liquids. In: Rudin A, Choi P, editors. The Elements of Polymer Science \& Engineering (Third Edition). Boston: Academic Press; 2013. p. 149-229. 
[47] Stachowiak GW, Batchelor AW. 2 - Physical Properties of Lubricants. In: Stachowiak GW, Batchelor AW, editors. Engineering Tribology (Third Edition). Burlington: Butterworth-Heinemann; 2006. p. 11-50.

[48] ISO. ISO 19906: Petroleum and Natural Gas Industries - Arctic Offshore Structures. Geneva: ISO; 2010.

[49] Pilcher JJ, Nadler E, Busch C. Effects of hot and cold temperature exposure on performance: a meta-analytic review. Ergonomics. 2002;45:682-98.

[50] Šaltytė Benth J, Benth FE. A critical view on temperature modelling for application in weather derivatives markets. Energy Economics. 2012;34:592-602.

[51] Wakaura M, Ogata Y. A time series analysis on the seasonality of air temperature anomalies. Meteorological Applications. 2007;14:425-34.

[52] Benth Jš, Benth FE, Jalinskas P. A Spatial-temporal Model for Temperature with Seasonal Variance. Journal of Applied Statistics. 2007;34:823-41.

[53] Alexandridis AK, Zapranis AD. Weather derivatives - Modeling and Pricing WeatherRelated Risk. New York: Springer; 2013.

[54] Taib CMIC, Benth FE. Pricing of temperature index insurance. Review of Development Finance. 2012;2:22-31.

[55] Osczevski R, Bluestein M. The new wind chill equivalent temperature chart. Bulletin of the American Meteorological Society. 2005;86:1453-8.

[56] Bluestein M, Quayle R. Wind Chill. In: Holton JR, Curry JA, Pyle JA, editors. Encyclopedia of Atmospheric Sciences. Oxford: Academic Press; 2003. p. 2597-602.

[57] Benth FE, Šaltytė Benth J. Dynamic pricing of wind futures. Energy Economics. 2009;31:16-24.

[58] Benth JŠ, Benth FE. Analysis and modelling of wind speed in New York. Journal of Applied Statistics. 2010;37:893-909.

[59] Caporin M, Preś J. Modelling and forecasting wind speed intensity for weather risk management. Computational Statistics \& Data Analysis. 2012;56:3459-76.

[60] Department of Defense. Military Standard MIL-STD-721C - Definitions of terms for reliability and maintainability. Washington, DC: Department of Defense; 1981.

[61] Jardine AK, Tsang AH. Maintenance, replacement, and reliability: theory and applications. Boca Raton: CRC press; 2013.

[62] Zio E, Compare M. Evaluating maintenance policies by quantitative modeling and analysis. Reliability Engineering \& System Safety. 2013;109:53-65.

[63] Riane F, Roux 0, Basile 0, Dehombreux P. Simulation Based Approaches for Maintenance Strategies Optimization. In: Ben-Daya M, Duffuaa SO, Raouf A, Knezevic J, AitKadi D, editors. Handbook of Maintenance Management and Engineering. London: Elsevier; 2009. p. 133-53.

[64] Pierskalla WP, Voelker JA. A survey of maintenance models: the control and surveillance of deteriorating systems. Naval Research Logistics Quarterly. 1976;23:353-88. [65] Zio E, Aven T. Industrial disasters: Extreme events, extremely rare. Some reflections on the treatment of uncertainties in the assessment of the associated risks. Process Safety and Environmental Protection. 2013;91:31-45.

[66] Aven T, Zio E, Baraldi P, Flage R. Uncertainty in Risk Assessment: The Representation and Treatment of Uncertainties by Probabilistic and Non-Probabilistic Methods. West Sussex: John Wiley \& Sons; 2014. 